Article

\title{
Electrodeposition of Sn and Sn Composites with Carbon Materials Using Choline Chloride-Based Ionic Liquids
}

\author{
Ana T. S. C. Brandão ${ }^{1}\left(\right.$, Liana Anicai ${ }^{2}(0)$, Oana Andreea Lazar ${ }^{2}{ }^{(}$, Sabrina Rosoiu $^{2}{ }^{(}$, \\ Aida Pantazi ${ }^{2}$, Renata Costa ${ }^{1}$, Marius Enachescu ${ }^{2}\left(\mathbb{D}\right.$, Carlos M. Pereira $^{1, *(D)}$ and \\ A. Fernando Silva ${ }^{1}$ \\ 1 CIQUP, Faculdade de Ciências da Universidade do Porto, Departamento de Química e Bioquímica, \\ Rua do Campo Alegre, 687, 4169-007 Porto, Portugal; atscbrandao@gmail.com (A.T.S.C.B.); \\ renata.costa@fc.up.pt (R.C.); afssilva@fc.up.pt (A.F.S.) \\ 2 Politehnica University of Bucharest, Center of Surface Science and Nanotechnology, Splaiul Independentei \\ nr. 313, Sector 6, 060042 Bucharest, Romania; lanicai@itcnet.ro (L.A.); oana.lazar@cssnt-upb.ro (O.A.L.); \\ sabrina.rosoiu@cssnt-upb.ro (S.R.); aida.pantazi@cssnt-upb.ro (A.P.); marius.enachescu@cssnt-upb.ro (M.E.) \\ * Correspondence: cmpereir@fc.up.pt
}

Received: 29 October 2019; Accepted: 25 November 2019; Published: 27 November 2019

check for updates

\begin{abstract}
Nano carbons, such as graphene and carbon nanotubes, show very interesting electrochemical properties and are becoming a focus of interest in many areas, including electrodeposition of carbon-metal composites for battery application. The aim of this study was to incorporate carbon materials (namely oxidized multi-walled carbon nanotubes (ox-MWCNT), pristine multi-walled carbon nanotubes (P-MWCNT), and reduced graphene oxide ( $\mathrm{CGO})$ ) into a metallic tin matrix. Formation of the carbon-tin composite materials was achieved by electrodeposition from a choline chloride-based ionic solvent. The different structures and treatments of the carbon materials will create metallic composites with different characteristics. The electrochemical characterization of Sn and Sn composites was performed using chronoamperometry, potentiometry, electrochemical impedance, and cyclic voltammetry. The initial growth stages of Sn and Sn composites were characterized by a glassy-carbon (GC) electrode surface. Nucleation studies were carried out, and the effect of the carbon materials was characterized using the Scharifker and Hills (SH) and Scharifker and Mostany (SM) models. Through a non-linear fitting method, it was shown that the nucleation of Sn and Sn composites on a GC surface occurred through a 3D instantaneous process with growth controlled by diffusion. According to Raman and XRD analysis, carbon materials were successfully incorporated at the Sn matrix. AFM and SEM images showed that the carbon incorporation influences the coverage of the surface as well as the size and shape of the agglomerate. From the analysis of the corrosion tests, it is possible to say that $\mathrm{Sn}$-composite films exhibit a comparable or slightly better corrosion performance as compared to pure Sn films.
\end{abstract}

Keywords: electrodeposition; Sn composite; carbon materials; multi-walled carbon nanotubes; reduced graphene oxide; deep eutectic solvents; choline chloride

\section{Introduction}

\subsection{Sn Electrodeposition in ILs}

Metal electrodeposition is crucial for a variety of industrial applications, where particularly Sn has been applied as a coating due to its non-toxicity, ductility, and corrosion resistance [1]. Walsh et al. [2] published an extensive investigation regarding the available information about Sn electrodeposition. 
Due to their physical and chemical characteristics, Sn coatings are regularly used in food containers production, automotive part, and electronic components, among others. The excellent ductility of Sn allows the coated substrate to be processed and to present multiple shapes without damaging the coating properties [2].

Habboush et al. [3] presented ionic liquids (ILs) to replace aqueous baths, in order to reduce the hydrogen evolution effects. The ultimate difference between ILs and aqueous electrolyte solutions is their internal composition. ILs are conducting liquids fully constituted of ions, while in conventional electrolyte solutions, molecular solvents solvate the ions and play an important role in the electrochemical performance of the solution [4]. One of the drawbacks of ILs is that some of them are solid or very viscous at room temperature; thus making them unusable as electrolytes. Moreover, their high cost and sensitivity to the presence of water limit their general use. More recently, Abbott et al. introduced deep eutectic solvents (DESs) as an alternative ionic solvent for metal electrodeposition [5]. The most used DESs are based on quaternary ammonium salts as eutectic mixtures with different hydrogen bond donor compounds, such as amides, glycols or carboxylic acids [6]. This is a novel ionic solvent medium with exciting potential in metals and alloys electrodeposition [7-12]. DESs are considered as a new class of IL analogs because they have similar physical properties to ILs $[13,14]$. Although DESs are not constituted solely of ions and the neutral molecules play an important role in the formation of the ionic solution and on their electrochemical behavior, their physico-chemical behavior is similar to that of the ILs. The crucial distinction between ILs and DESs is that reduced melting points in DESs are achieved via the added hydrogen bond donors (HBD), rather than changing the structure of the ions [15].

Metal and alloys electrodeposition from aqueous electrolytes is limited by the narrow electrochemical window and hydrogen evolution. In order to overcome that, ILs are attracting attention as promising alternatives for several electrochemical processes due primarily to a large potential window, the acceptable ionic conductivity, high thermal stability, and negligible vapor pressure [7].

Abbott et al. studied the Zn-Sn alloy [5] and Zn [16] electrodeposition from urea and ethylene glycol/choline chloride-based DES, showing that the response and morphology is dependent on the used DES. Also, a preliminary study of the nucleation mechanism for Zn electrodeposition using reline (choline chloride: urea) and ethaline (choline chloride: ethylene glycol) was reported by Abbott et al. [17].

Several investigations regarding Sn electrodeposition in different ILs can be found in the literature [18-22]. Cojocaru et al. [23] investigated tin-nickel (Sn-Ni) alloy electrodeposition involving choline chloride: A urea eutectic mixture with dissolved metal chloride hydrated salts, where adherent and compact dark-grey Sn-Ni alloy deposits were obtained. Salomé et al. [24] presented a thorough study on the nucleation mechanism and the kinetic parameters for Sn deposition. Anicai and co-workers [25] presented a detailed investigation of the electrodeposition and corrosion behavior of Sn and Sn-Ni alloys coatings from two choline chloride-based ionic liquids, respectively: choline chloride-ethylene glycol and choline chloride-malonic acid.

\subsection{Sn-Carbon Nanomaterials Composites}

Graphene is an atomically thin two-dimensional $\mathrm{sp}^{2}$ bonded carbon sheet, exhibiting remarkable properties such as excellent thermal and electrical conductivity, mechanical strength, optical, and remarkable electrochemical properties [26].

Carbon nanotubes (CNTs) consist in a graphene sheet rolled with a cylindrical shape, being atomically smooth, with exceptional properties such as high mechanical strength. CNTs are one of the allotropes of carbon with $\mathrm{sp}^{2}$-hybridization and can be produced as single- (S), double- (D) and multi-walled (MW) CNTs, the concentric cylindrical planes interacting by Van der Waals forces when the CNTs have more than one wall [27]. CNTs have received special attention since their discovery in 1991 [28], since they are becoming very attractive in various applications such as for the fabrication of 
electronic devices and catalysts [29]. The electrochemical properties are strongly influenced by the structure (defects) and functional groups incorporated in the CNTs [26]. The potential for reinforced metal deposits with CNTs due to its extraordinary specific stiffness and strength [30] represents a tremendous opportunity for the development of new materials, now being an exponentially growing area of research interest.

The incorporation of CNTs into metal matrixes is still a challenge. Few research groups have succeeded in preparing CNTs composites with a variety of metals [31-37].

Corrosion and abrasion are the most significant reasons for the degradation of metals. For that reason, extensive research is being conducted to develop methods to diminish this problem. Carbon materials, mainly CNTs, are said to be the ideal reinforcement to solve this problem, because of their attractive properties [38]. In the past few years, the attention regarding metal composites namely $\mathrm{Sn}$-carbon materials composites has increased due to its possible application as an anode for lithium-ion batteries, due to the excellent characteristics of carbon. Several authors have developed research regarding this topic [35,39-44]. Few studies have been made for metal-CNTs composites electrodeposition from DES-based systems. Martis et al. [45] studied the Ni-MWCNT composite electrodeposition on a $\mathrm{Cu}$ substrate using a ChC-lU eutectic mixture and successfully found that composites involving oxidized MWCNTs present higher stability and better corrosion resistance when compared to pristine MWCNTs. Pereira and co-workers [46] recently reported the successful electrodeposition of Co composites with MWCNT using ChCl-U eutectic mixture. It was found that the presence of MWCNTs contributed to decreasing the deposit's roughness. The Co-MWCNT composite coatings appeared to exhibit a comparable or slightly better corrosion performance than that of pure Co ones, in particular for long term exposure to $0.5 \mathrm{M} \mathrm{NaCl}$ solution.

To the best of our knowledge, there are no studies regarding the electrodeposition of Sn-carbon composites, such as MWCNTs and reduced graphene oxide (rGO), in DES-based choline chloride-ethylene glycol (ethaline). The present paper aims to investigate the electrodeposition of Sn-MWCNTs (oxidized (ox-) and pristine (-P)) as well as of Sn-rGO composites from choline chloride: ethylene glycol eutectic mixture. Besides, nucleation parameters, roughness, and conductivity of the coatings were characterized according to the type of composite. This may be very important for developing metal composites with high specific surface area carbon materials for further application as electrodes in batteries.

\section{Materials and Methods}

\subsection{Chemicals and Preparation of DES}

Choline chloride ( $\mathrm{ChCl}$ ) (Aldrich, 99\%) was dried in an oven overnight before use and ethylene glycol (EG) and tin (Sn (II)) chloride (Aldrich, 97\%) were used as received. Ethaline is formed by mixing $\mathrm{ChCl}$ and $\mathrm{EG}$ in a molar ratio of 1:2.

The experimental procedure described below was adapted from that already presented by Salomé and co-workers [24].

The eutectic mixture was formed by stirring the two components directly in the electrochemical cell, at $75{ }^{\circ} \mathrm{C}$, until forming a homogeneous, colorless liquid. Before any experiment, the solutions were deaerated with nitrogen and the cell was kept under nitrogen flow during all electrochemical measurements. A mixture of $0.01 \mathrm{M} \mathrm{Sn}$ (II) and $0.5 \mathrm{~g} / \mathrm{L}$ of carbon materials (ox-MWCNT/ P-MWCNT/ rGO) was used with ethaline as an electrolyte. Different compositions of $\mathrm{Sn}$ and carbon materials are presented for surface analysis, and the designation will be presented when necessary.

\subsection{Electrode Preparation}

A three electrode system of GC (Metrohm) or Cu plate electrodes as working electrodes, a glassy carbon counter electrode and a silver wire reference electrode were used. GC working electrode was polished to obtain a mirror-like finish before each measurement using a $1-\mu \mathrm{m}$ diamond suspension 
(Buehler) followed by $0.5 \mu \mathrm{m}$ alumina powder (Buehler) and dried with nitrogen flow prior to all measurements. According to Salomé et al. [24], this method of surface treatment and preparation provides electrochemically reproducible surface properties and roughness that are suitable for the nucleation studies. The metallic precursor was dissolved in the cell under agitation and nitrogen flow. $\mathrm{Cu}$ was immersed in $\mathrm{H}_{2} \mathrm{O}: \mathrm{HNO}_{3}$ (1:1) solution before electrodeposition, followed by rinsing with distilled water and drying. The coatings investigated using SEM, AFM, Raman, and XRD were deposited onto $\mathrm{Cu}$-metallic substrates.

\subsection{Electrochemical measurements}

Electrochemical measurements were performed using a computer-controlled AUTOLAB PSTAT 10 from Eco Chemie, controlled with GPES 4.8 software. The experiments were performed at $75{ }^{\circ} \mathrm{C}$ and were carried out at a $20 \mathrm{mV} / \mathrm{s}$ scan rate, starting at $0 \mathrm{mV}$ and scanning towards negative potentials to $-1.1 \mathrm{~V}$.

\subsection{Surface Analysis}

The morphological and electrical properties study of the Sn and nano-carbon-based Sn coatings was carried out using a PicoLE Nano-Observer Atomic Force Microscope (AFM) equipment (PicoScan 2100, Les Ulis, France), operated in contact mode, using SPM conductive probes, with a resonance frequency between 5 to $25 \mathrm{kHz}$. The image processing was performed with Gwyddion 2.53 software.

A more detailed investigation of the coatings surface morphologies was carried out using Hitachi SU 8230 Scanning Electron Microscopy (SEM) equipment (Krefeld, Germany).

The structural properties of the prepared materials were studied by a Rigaku D/teX Ultra 250 X-Ray Diffraction (XRD) system (Isenburg, Germany), and the phase and structure of the metallic deposits (with a Cu Ka radiation of $1.5405 \AA$ ) were obtained with Scherrer Equation (1) [47]:

$$
D=\frac{k \lambda}{\beta \cos \theta}
$$

where $D$ is the crystallite size, $k$ is the Scherrer constant, $\lambda$ is the wavelength of the $X$-ray, $\beta$ is the full width at half maximum, and $\theta$ is the diffraction angle.

The Raman studies of all samples were carried out at room temperature by Confocal Micro-Raman Spectroscopy (Lier, Belgium), using a LabRam HR800 system. All the Raman spectra were generated by exposing the specimens for $100 \mathrm{~s}$ to $0.85 \mathrm{~mW}, 532 \mathrm{~nm}$ wavelength green laser and dispersing the sample emitted signal onto the CCD detector using 600 lines/mm grating.

\subsection{CNTs Functionalization}

The experimental procedure for the chemical functionalization of the CNTs (Sigma Aldrich, $>90 \%$ carbon basis, about $110-170 \mathrm{~nm}$ in outer diameter and $5-9 \mu \mathrm{m}$ in length) was adapted from the literature [48]. In an oxidation treatment, $125 \mathrm{~mL}$ of $\mathrm{H}_{2} \mathrm{SO}_{4}: \mathrm{HNO}_{3}(3: 1)$ solution was heated at $80{ }^{\circ} \mathrm{C}$ with $1 \mathrm{~g}$ of MWCNTs for $8 \mathrm{~h}$. After the heat treatment, the solution was allowed to cool until ambient temperature. The recovered CNTs were washed several times with Millipore water to remove the excess of acid (achieving $\mathrm{pH}=7$ ) and dried overnight in the oven at $60^{\circ} \mathrm{C}$. Different groups were introduced in the CNT surface, such as carboxylic acids, carbonyls, anhydrides, phenols, quinones, and lactones.

\subsection{Preparation of $r G O$}

rGO was obtained from graphite powder by following the Hummers and Offeman method [49]. Two grams of of graphite powder, $2.0 \mathrm{~g}$ of $\mathrm{KNO}_{3}$ and $6.0 \mathrm{~g}$ of $\mathrm{KMnO}_{4}$ were added to $40 \mathrm{~mL}$ of concentrated $\mathrm{H}_{2} \mathrm{SO}_{4}$ under vigorous stirring at $0{ }^{\circ} \mathrm{C}$. The mixture was then stirred continuously for $1 \mathrm{~h}$ at room temperature. After that, $160 \mathrm{~mL}$ of water was added to the mixture and the temperature 
was increased up to $95^{\circ} \mathrm{C}$, being kept at this temperature for $15 \mathrm{~min}$ and then poured into $240 \mathrm{~mL}$ of ultrapure water.

Then $\sim 16 \mathrm{~mL}$ of $\mathrm{H}_{2} \mathrm{O}_{2}$ was added into the suspension, being immediately cooled to room temperature; the solid products were filtered, washed with $5 \% \mathrm{HCl}$ aqueous solution and water, and dried. The obtained solid was dispersed in water to yield a yellow-brown suspension $(1 \mathrm{mg} / \mathrm{mL})$. This suspension was ultrasonicated for $10 \mathrm{~min}$ and then centrifuged at $500 \mathrm{rpm}$ for $5 \mathrm{~min}$ to remove the unexfoliated graphite oxide particles from it. Reduction of rGO was obtained through the use of hydrazine, using the procedure presented by Park et al. [50].

\subsection{Carbon Materials Dispersion in DES}

Carbon materials were added to the prepared DES and kept in an ultrasonic bath for $30 \mathrm{~min}$ to obtain a homogeneous dispersion. Stirring was kept during electrodeposition.

\subsection{Corrosion Studies}

A preliminary assessment of corrosion behavior of the electrodeposited Sn and Sn composites has been performed through continuous immersion in aerated $0.5 \mathrm{M} \mathrm{NaCl}$ solution at room temperature for $96 \mathrm{~h}$, with periodical visual examinations after 24, 48, 72, and $96 \mathrm{~h}$.

Potentiodynamic polarization curves were recorded against Ag reference electrode and a glassy carbon counter electrode at a sweeping rate of $5 \mathrm{mV} / \mathrm{s}$, and electrochemical impedance spectroscopy (EIS) was performed at open-circuit potential (OCP), both techniques using $0.5 \mathrm{M} \mathrm{NaCl}$ solution. The geometrical surface of the working electrode was $12.5 \mathrm{~cm}^{2}$. EIS was recorded using a $10 \mathrm{mV}$ ac perturbation, within $100 \mathrm{kHz}-50 \mathrm{mHz}$ frequency range, being processed using FRA software (Autolab 4.9).

\section{Results and Discussion}

The major task in this work is to understand how carbon material dispersion interferes with the conventional Sn electrodeposition. Several studies were performed, such as voltammetric, chronoamperometric and potentiometric experiments as well as AFM, SEM, XRD, and Raman analysis of the Sn-carbon composites' surface.

\subsection{Voltammetric Experiments}

Dispersions of different carbon materials in $\mathrm{ChCl}$ :EG eutectic mixture were prepared. The stability of the dispersion in the bath is a key factor to obtain a metal/carbon composite. It has been noticed that there is an excellent dispersion stability of the involved carbon nanomaterials in the eutectic solvent used.

In order to get information on the electrochemical process, cyclic voltammetry has been recorded at $20 \mathrm{mV} / \mathrm{s}, 75^{\circ} \mathrm{C}$, involving a GC electrode, as illustrated in Figure 1.

The cathodic deposition process in $\mathrm{ChCl}$ :EG electrolyte, with a single cathodic peak, starts at around $-0.45 \mathrm{~V}$ for all composites. The cathodic peaks for carbon materials shift to more positive potentials, compared to pure Sn. Scanning in the positive direction, a single anodic peak for all composites is evidenced at about $-0.35 \mathrm{~V}$, assigned to the $\mathrm{Sn}$ composites stripping from the GC working electrode surface.

The introduction of carbon materials on the Sn matrix led to an increase and dislocation towards positive values of the cathodic peak (for ox-MWCNTs and P-MWCNTs), with exception to the Sn-rGO composite, when compared to pure Sn.

Scanning in the positive direction showed that the introduction of ox-MWCNTs increased the current density of the anodic peak, which does not happen for P-MWCNTs and rGO, when compared to pure Sn. 


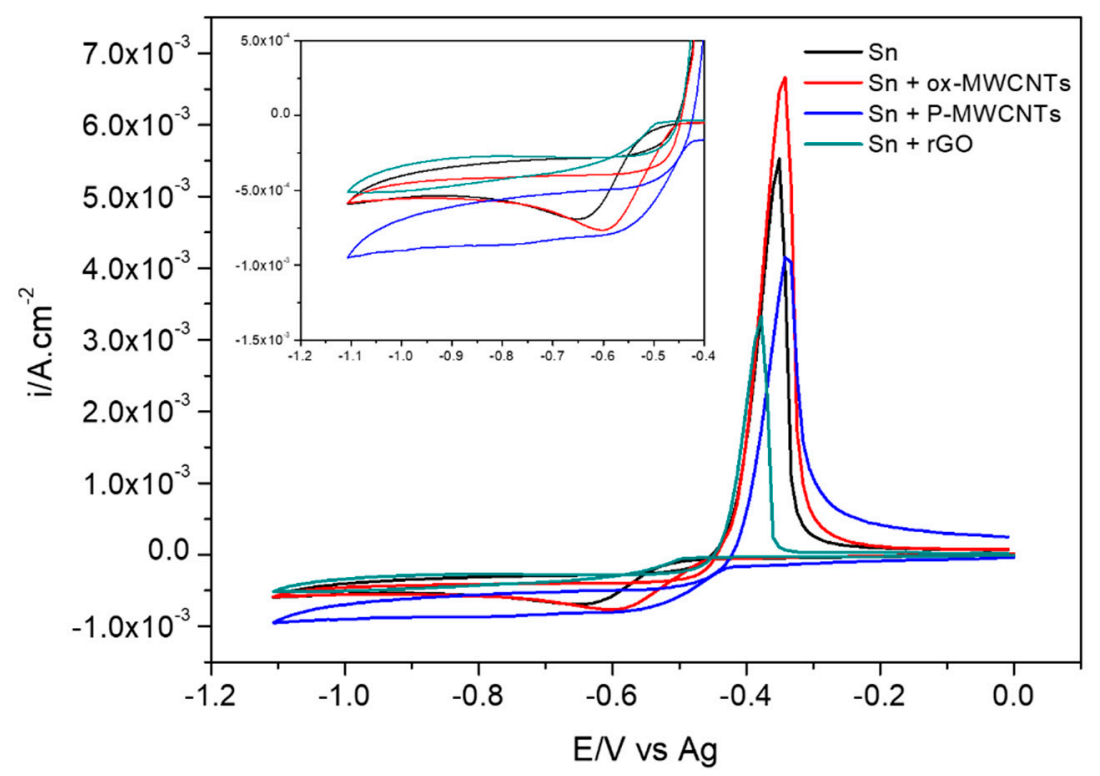

Figure 1. Cyclic voltammogram on GC electrode in ChCl:EG ionic liquid for $0.01 \mathrm{M} \mathrm{Sn}$ (II) + $0.5 \mathrm{~g} / \mathrm{L}$ Carbon materials (ox-MWCNT/P-MWCNT/ rGO), at $75{ }^{\circ} \mathrm{C}$ and $20 \mathrm{mV} / \mathrm{s}$. Inset graph presents the cathodic region of the cyclic voltammogram.

\subsection{Chronoamperometry}

For nucleation studies, carbon is the ideal substrate due to the fact the polished glassy carbon surface has randomly distributed active sites [51]. The Scharifker and Hills (SH) model [52] is the most used to identify the nucleation mechanism of metal deposition from water-based baths and DES.

Metal deposition on a foreign substrate usually occurs via 3D nucleation process, and the $\mathrm{SH}$ model considers two limiting cases, instantaneous (IN) and progressive (PN) nucleation [52-54]. In the first case, all the nuclei are formed immediately after the potential step, and in the second one, the nuclei formation is time-dependent. Equations (2) and (3) present the instantaneous and progressive growth, respectively.

$$
\begin{aligned}
& \frac{i^{2}}{i_{\max }^{2}}=\frac{1.9542}{\frac{t}{t_{\max }}}\left\{1-\exp \left[-1.2564\left(\frac{t}{t_{\max }}\right)\right]^{2}\right. \\
& \frac{i^{2}}{i_{\max }^{2}}=\frac{1.2254}{\frac{t}{t_{\max }}}\left\{1-\exp \left[-2.3367\left(\frac{t}{t_{\max }}\right)^{2}\right]^{2}\right.
\end{aligned}
$$

where $i$ is the current density, $i_{\max }$ is the maximum current density, $t$ is the time, and $t_{\max }$ is the time at the maximum current. The experimental current-time transient curves were analyzed using the expression (Equations (2) and (3)), with $i_{\max }$ and $t_{\max }$ obtained experimentally.

Figure 2 presents the chronoamperograms for $\mathrm{Sn}$ and $\mathrm{Sn}$-carbon material composites for different potentials $(-500 \mathrm{mV}$ to $-575 \mathrm{mV}$ ). The current density goes through a minimum and then increases until a current maximum, $i_{\max }$, is reached at time, $t_{\max }$, from which the current starts to decrease. As the potential goes to more negative values, $i_{\text {max }}$ increases and $t_{\max }$ decreases. This is a typical behavior of deposition with nucleation and growth processes $[51,55,56]$. 
(a) $0.01 \mathrm{M}$ Sn (II)

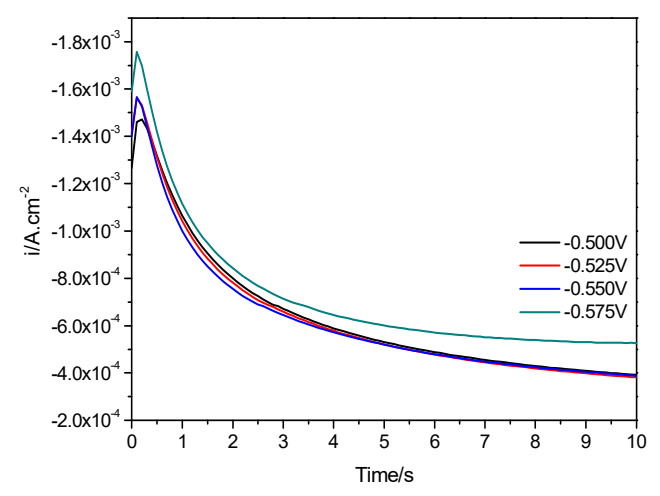

(c) $0.01 \mathrm{M} \mathrm{Sn}$ (II) $+0.5 \mathrm{~g} / \mathrm{L}$ P-MWCNTs

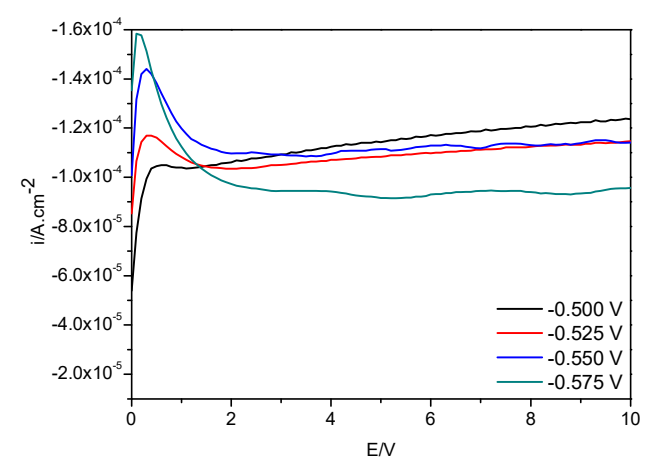

(b) $0.01 \mathrm{M}$ Sn (II) $+0.5 \mathrm{~g} / \mathrm{L}$ ox-MWCNTs

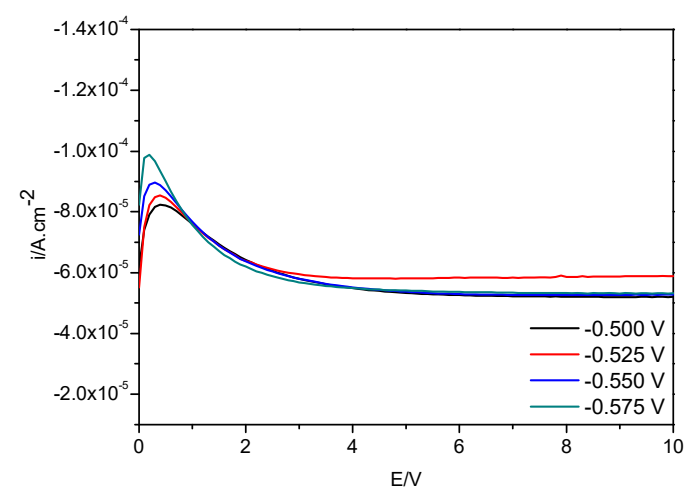

(d) $0.01 \mathrm{M} \mathrm{Sn}$ (II) $+0.5 \mathrm{~g} / \mathrm{L} \mathrm{rGO}$

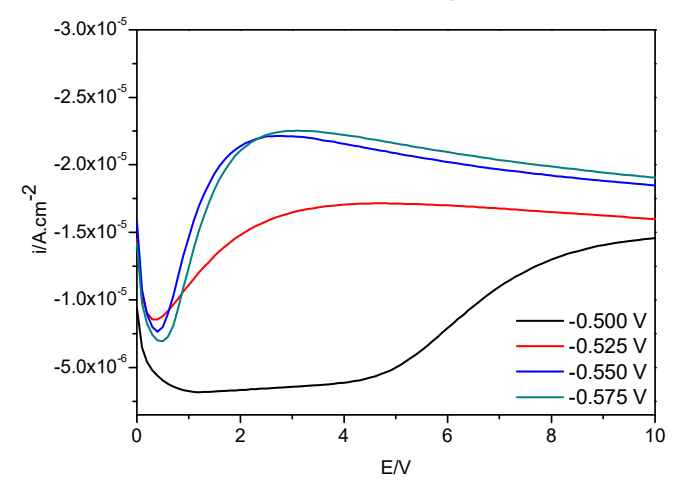

Figure 2. Chronoamperograms of Sn composites deposition on GC electrode containing $0.01 \mathrm{M}$ Sn(II) and $0.5 \mathrm{~g} / \mathrm{L}$ ((a) 0.01 M Sn(II), (b) 0.01 M Sn (II) + 0.5 g/L ox-MWCNTs, (c) $0.01 \mathrm{M} \mathrm{Sn} \mathrm{(II)} \mathrm{+} 0.5 \mathrm{~g} / \mathrm{L}$ P-MWCNTs, and (d) $0.01 \mathrm{M}$ Sn (II) + $0.05 \mathrm{~g} / \mathrm{L} \mathrm{rGO)}$.

From the experimental results, it is possible to observe a strong effect of the presence of the carbon materials, in particular when $0.5 \mathrm{~g} / \mathrm{L} \mathrm{rGO}$ is added. This effect is clear, both at $t_{\max }$ and $i_{\max }$ (Table 1 ) and is the evidence of the incorporation of rGO into the Sn matrix. In the case of the incorporation of the MWCNTs (both ox-MWCNTs and P-MWCNTs), there is also a net effect of the carbon material on the Sn nucleation process, although not so strong as shown by the very slight changes in the values of $t_{\max }$ and $i_{\max }$. The comparison of the experimental plots with the theoretical curves, obtained from the Equations (2) and (3), was made as a preliminary test of the experimental data and can be seen in Figure S1. For all Sn and Sn-composites, it follows instantaneous growth at all studied potentials (only $-0.550 \mathrm{~V}$ potential is presented in Figure S1). At an early stage, the experimental data presents similar results to the theoretical models, but for values higher than $t_{\max }$, the deviations are higher with the introduction of carbon materials.

Experimental data were fitted to Equations (2) and (3) using the non-linear fitting method from Origin 8 software, and extracted data is displayed in Table 1.

Besides the experimental parameter $t_{\max }, i_{\max }$ presents the nucleation parameters $N_{0}$ (nuclei population density), $D$ (diffusion coefficient) and $A$ (nucleation frequency). $t_{\max }$ and $i_{\max }$ are calculated from the chronoamperometric curves at different potentials. $N_{0}$ and $D$ are determined from the SH model [52], where $D$ is obtained experimentally from plot $i_{\max }$ vs. $t_{\max }{ }^{-1 / 2}$ (Cottrell equation [53] Equation (4)), and $\mathrm{N}_{0}$ is obtained by the proposed algebraic equation as presented by Grujicic [53] (Equation (5)). 


$$
\begin{gathered}
i=\frac{n F D^{\frac{1}{2}} C_{0}}{\pi^{\frac{1}{2}} t^{\frac{1}{2}}} \\
N_{0}=0.065\left(\frac{1}{8 \pi C_{0} V_{m}}\right)^{\frac{1}{2}}\left(\frac{n F C_{0}}{i_{\text {max }} t_{\max }}\right)^{2}
\end{gathered}
$$

where, $i$ is the current density; $n$, number of electrons involved; $F$, Faraday constant; $C_{0}$, concentration of species in the bulk; $V_{\mathrm{m}}$, molar volume; and $\mathrm{t}$, time.

The $A$ parameter was determined using Equation (6) through the SM method presented by Sebastián et al. [57] using the "fsolve" tool in Matlab software.

$$
i(t)=\frac{n F \sqrt{D} c}{\sqrt{\pi t}}\left(1-\exp \left(-N_{0} \pi k^{*} D\left(t-\frac{1}{A}(1-\exp (-A t))\right)\right)\right)
$$

\begin{tabular}{|c|c|c|c|c|c|c|}
\hline & Potential/V & $t_{\max } / \mathrm{s}$ & $i_{\max } / 10^{-5}$ A.cm ${ }^{-2}$ & $\mathrm{~N}_{0} / 10^{7} \mathrm{~cm}^{-2}$ & $\mathrm{D} / 10^{-7} \mathrm{~cm}^{-2} \mathrm{~s}^{-1}$ & $\mathrm{~A} / \mathrm{s}^{-1}$ \\
\hline \multirow{4}{*}{0.01 M Sn (II) } & -0.500 & 0.26 & -10.6 & 13.40 & 2.46 & 102.62 \\
\hline & -0.525 & 0.18 & -11.3 & 24.70 & 1.94 & 188.41 \\
\hline & -0.550 & 0.17 & -11.5 & 26.70 & 1.89 & 203.94 \\
\hline & -0.575 & 0.10 & -12.7 & 63.20 & 1.36 & 483.27 \\
\hline \multirow{4}{*}{$\begin{array}{c}0.01 \mathrm{M} \text { Sn (II) } \\
+ \\
0.5 \mathrm{~g} / \mathrm{L} \mathrm{ox}-\mathrm{MWCNT}\end{array}$} & -0.500 & 0.44 & -8.24 & 7.76 & 2.52 & 59.30 \\
\hline & -0.525 & 0.42 & -8.54 & 7.93 & 2.58 & 60.59 \\
\hline & -0.550 & 0.33 & -8.89 & 11.90 & 2.20 & 90.57 \\
\hline & -0.575 & 0.24 & -9.89 & 18.10 & 1.98 & 138.35 \\
\hline \multirow{4}{*}{$\begin{array}{c}0.01 \mathrm{M} \mathrm{Sn} \text { (II) } \\
+ \\
0.5 \mathrm{~g} / \mathrm{L} \mathrm{P}-\mathrm{MWCNT}\end{array}$} & -0.500 & 0.53 & -10.5 & 3.32 & 4.89 & 25.36 \\
\hline & -0.525 & 0.38 & -11.7 & 5.16 & 4.39 & 39.43 \\
\hline & -0.550 & 0.31 & -14.4 & 5.46 & 5.25 & 41.77 \\
\hline & -0.575 & 0.15 & -15.8 & 18.20 & 3.15 & 139.12 \\
\hline \multirow{4}{*}{$\begin{array}{c}0.01 \mathrm{M} \text { Sn (II) } \\
+ \\
0.5 \mathrm{~g} / \mathrm{L} \text { rGO }\end{array}$} & -0.500 & 3.30 & -2.36 & 1.68 & 1.54 & 12.91 \\
\hline & -0.525 & 1.91 & -2.71 & 3.84 & 1.18 & 29.34 \\
\hline & -0.550 & 2.33 & -3.05 & 2.08 & 1.80 & 15.88 \\
\hline & -0.575 & 1.25 & -3.73 & 4.69 & 1.47 & 35.86 \\
\hline
\end{tabular}

Table 1. Potential dependence of the free parameters for the Sn and Sn composites deposition according to the SM and SH models.

The value of $t_{\max }$ increases with the addition of carbon materials. $N_{0}$ values increase with increasing potential, which shows that the number of active sites increases exponentially as the potential becomes more negative. This behavior is typical for instantaneous nucleation [58]. More detailed information is presented in Figure 3, where the logarithmic value of $N_{0}$ is presented as a function of the applied potential for $\mathrm{Sn}$ and composites. $N_{0}$ is higher for $\mathrm{Sn}$, followed by ox-MWCNT, P-MWCNT, and rGO. 


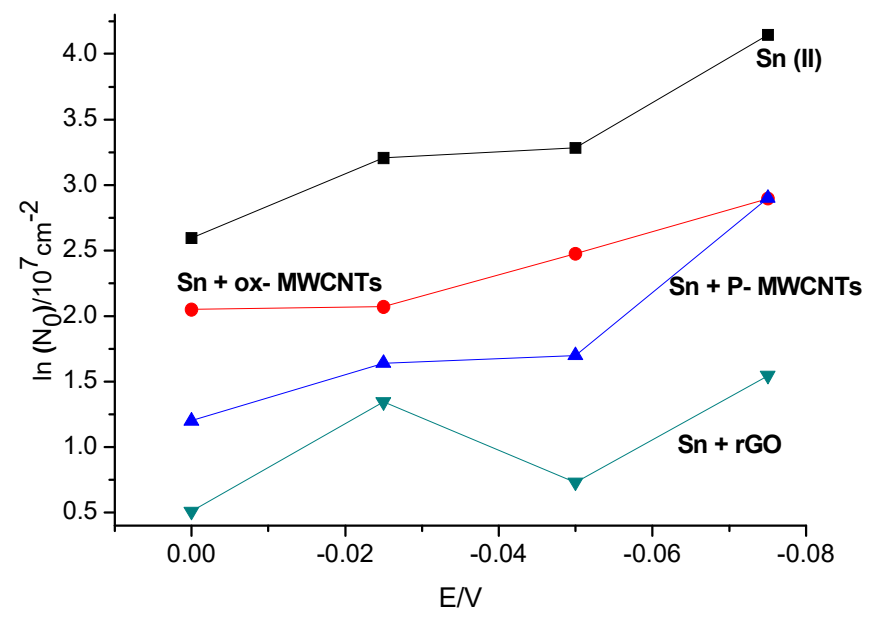

Figure 3. Plot of $\ln \left(N_{0}\right)$ vs. E for $S n$ and Sn-composites electrodeposition.

The average values of the diffusion coefficients of Sn (II) species were $1.77 \times 10^{-7} \mathrm{~cm}^{-2} \mathrm{~s}^{-1}, 2.32 \times$ $10^{-7} \mathrm{~cm}^{-2} \mathrm{~s}^{-1}, 4.42 \times 10^{-7} \mathrm{~cm}^{-2} \mathrm{~s}^{-1}$, and $1.49 \times 10^{-7} \mathrm{~cm}^{-2} \mathrm{~s}^{-1}$ for Sn, Sn-ox-MWCNT, Sn-P-MWCNT and Sn-rGO, respectively, which are relatively comparable with other reported values [24]. It should be noticed that there are higher values of the diffusion coefficient of Sn (II) species in the presence of P-MWCNT, which may facilitate a supplementary electron transfer route, thus enhancing the overall diffusion process to be more pronounced as compared to the other carbon nanomaterials.

\subsection{AFM Studies}

Samples of pure Sn and Sn composites were examined by AFM in contact mode. The dataset of AFM images $(20 \mu \mathrm{m} \times 20 \mu \mathrm{m})$, combined with maps of friction force and electrical conductivity, are presented in Figure 4.

A

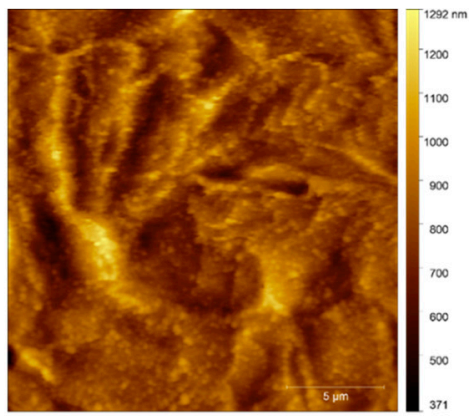

B

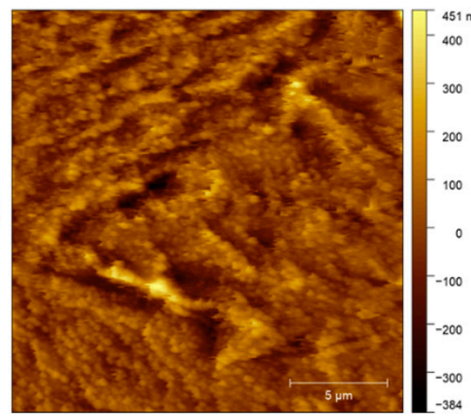

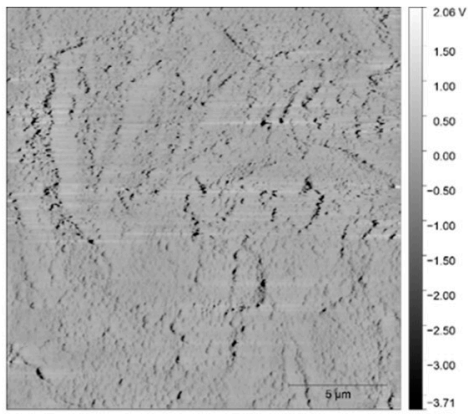
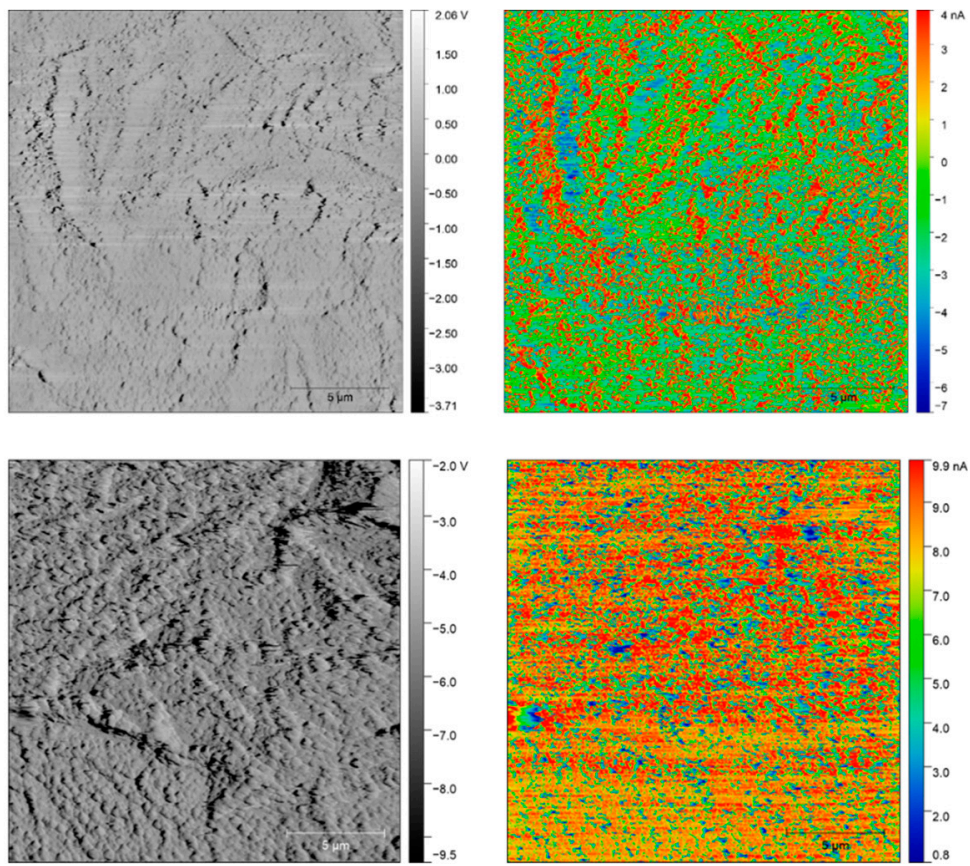

Figure 4. Cont. 
C
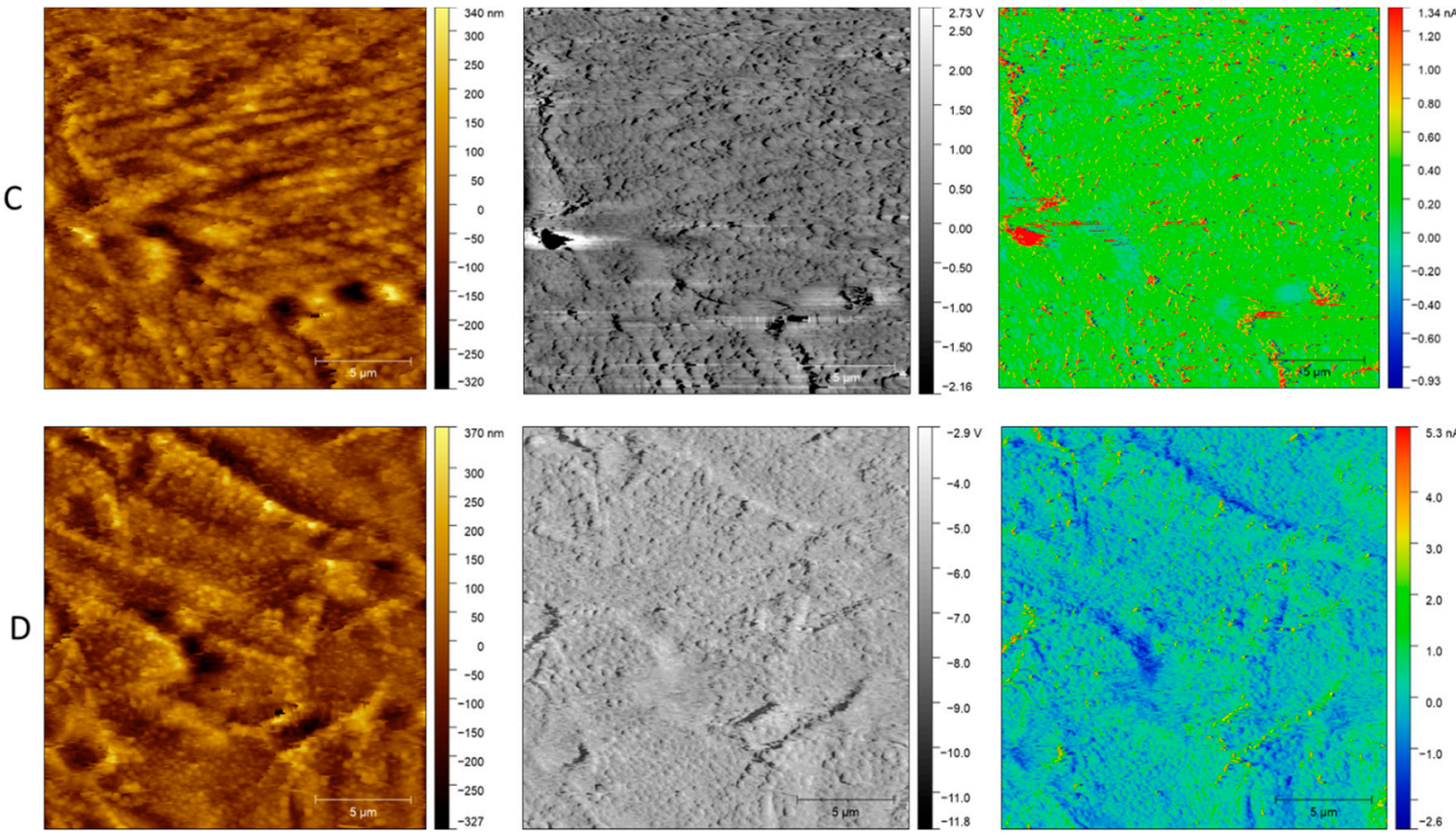

Figure 4. Topography, friction and electrical conductivity (bias voltage $=-1 \mathrm{~V}$ ) images, related to the Sn (A) and Sn composites ((B)-0.01 M Sn (II) + 0.5 g/L ox-MWCNT, (C)-0.01 M Sn (II)+ $0.5 \mathrm{~g} / \mathrm{L}$ P-MWCNT, and (D)—0.01 M Sn (II) + 0.5 g/L rGO). Deposits obtained by chronoamperometry using the following experimental conditions: $-1.25 \mathrm{~V}, \mathrm{Cu}$ substrate, $\mathrm{T}=75^{\circ} \mathrm{C}, 600 \mathrm{~s}$ ).

The topography images show for all the samples a surface with round particles with average diameter of $0.254 \mu \mathrm{m}$ for pure Sn, followed by $0.428 \mu \mathrm{m}$ for Sn + ox-MWCNTs, $0.352 \mu \mathrm{m}$ for Sn + P-MWCNTs, and $0.412 \mu \mathrm{m}$ for $\mathrm{Sn}+\mathrm{rGO}$. The height variation does not allow the identification of the MWCNTs or rGO in the topographic image.

Data presented in Table 2 show that by adding dispersed MWCNTs (ox- and P-), the roughness (Ra) and the root mean square roughness (RMS) increased, compared to pure Sn. However, Sn + ox-MWCNTs presented higher values of roughness compared to Sn + P-MWCNTs. Sn + rGO presents lower values of roughness compared to MWCNTs.

Table 2. Surface roughness and conductivity values of coatings related to the $\mathrm{Sn}(\mathrm{A})$ and Sn composites, namely 0.01 M Sn (II)+ 0.5 g/L ox-MWCNT (B), 0.01 M Sn (II)+ 0.5 g/L P-MWCNT (C), and 0.01M Sn (II) $+0.5 \mathrm{~g} / \mathrm{L}$ rGO (D). Deposits obtained by chronoamperometry using the following experimental conditions: $-1.25 \mathrm{~V}, \mathrm{Cu}$ substrate, $\left.\mathrm{T}=75^{\circ} \mathrm{C}, 600 \mathrm{~s}\right)$.

\begin{tabular}{ccccc}
\hline & \multicolumn{2}{c}{ Topography/nm } & \multicolumn{2}{c}{ Conductivity/nA } \\
\cline { 2 - 5 } & Ra & RMS & Ra & RMS \\
\hline $\mathbf{0 . 0 1}$ M Sn (II) & 23.0 & 29.6 & 2.60 & 3.00 \\
\hline $\mathbf{0 . 0 1}$ M Sn (II) + 0.5 g/L ox-MWCNT & 61.8 & 82.0 & 2.69 & 3.12 \\
\hline $\mathbf{0 . 0 1}$ M Sn (II) + 0.5 g/L P-MWCNT & 59.8 & 75.6 & 0.172 & 0.261 \\
\hline $\mathbf{0 . 0 1}$ M Sn (II) + 0.5 g/L rGO & 53.5 & 72.3 & 0.409 & 0.595 \\
\hline
\end{tabular}

Friction force maps show the variation of friction in the sample, from high friction regions (bright) to low friction regions (dark) [59]. There are no contrasting regions which did not allow to identify the presence of carbon materials.

Conducting atomic force microscopy can map the changes in the surface conductivity using a metallic conducting probe in contact mode, where the parameter goes from high conductivity zones 
(red) to low conductivity zones (blue). Table 2 presents also the values for $\mathrm{R}_{\mathrm{a}}$ and RMS related to the conductivity studies. Pure Sn deposit shows regions with high conductivity and several regions with lesser conductivity values. For pure $\mathrm{Sn}$, the average conductivity value is $2.60 \mathrm{nA}$, increasing with the introduction of ox-MWCNTs (2.69 nA) and drastically decreasing for P-MWCNTs $(0.17 \mathrm{nA})$ and rGO $(0.40 \mathrm{nA})$.

Analyzing the C-AFM data, it is possible to observe that the surface conductivity diminished with the incorporation of carbon materials, with the exception of the ox-MWCNTs. This may indicate that the incorporation of oxygen functional groups (phenols, sulfonic acids, quinones, thiols, carboxylic acids, carbonyls, anhydrides ... ) in the MWCNT can help to slightly increase the conductivity of the Sn deposit. The amorphous carbon present in the deposit may explain the accentuated decrease in the conductivity in the presence of P-MWCNTs and rGO.

Figure 5 presents the 3D topographic AFM images of Sn and composites, where it is visible that with carbon materials the maximum height increases, when comparing with pure Sn.

A

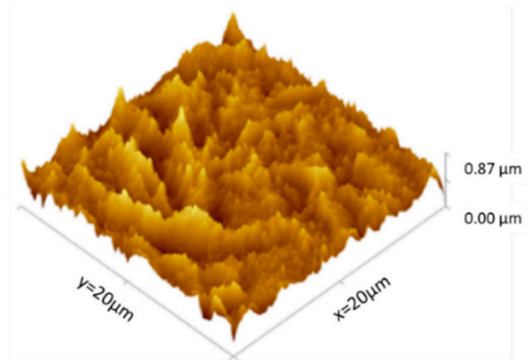

C

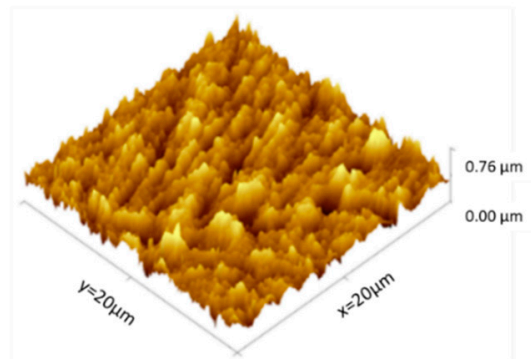

B

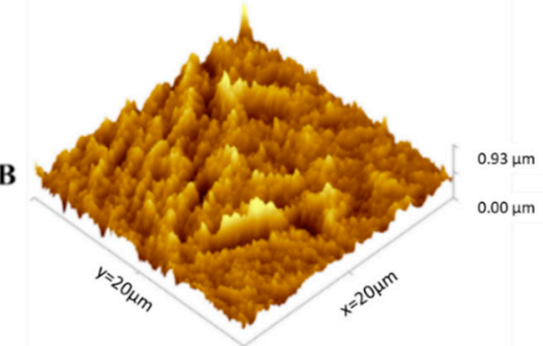

D

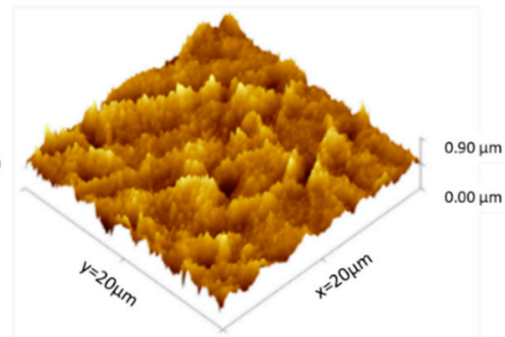

Figure 5. 3D topographic AFM images of Sn (A) and Sn composites, namely 0.01M Sn (II)+ $0.5 \mathrm{~g} / \mathrm{L}$ ox-MWCNT (B), 0.01 M Sn (II) + 0.5 g/L P-MWCNT (C), and 0.01 M Sn (II) + 0.5 g/L rGO (D). Deposits obtained by chronoamperometry using the following experimental conditions: $-1.25 \mathrm{~V}$, Cu substrate, $\mathrm{T}=75^{\circ} \mathrm{C}, 600 \mathrm{~s}$.

\subsection{SEM Studies}

An extensive analysis of the surface of the Sn-composite coatings will be made through SEM analysis. Chronoamperometric and potentiometric techniques will be used for assessing voltage and current effect on the electrodeposition of these composites.

As shown in Figure 6, the morphology of pure Sn on the Cu substrate appears to be formed by well-defined molten particles, covering the entire surface. Increasing the applied voltage (Figure 6A,B), there is an increase in the particles size. Preparing the deposit at constant applied current (Figure 6C,D) creates a different aspect of the formed particles. 

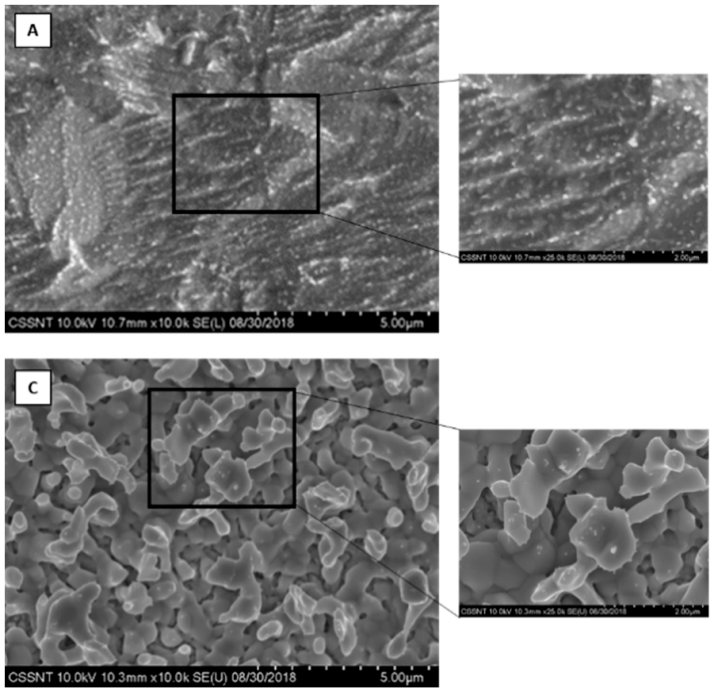
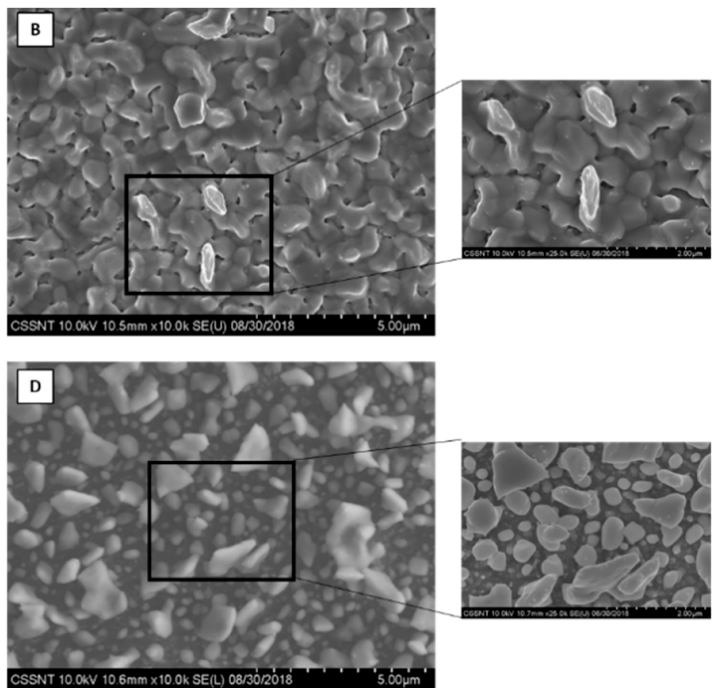

Figure 6. SEM images for Sn coatings prepared at $75^{\circ} \mathrm{C}$, by chronoamperometry $(\mathbf{A}, \mathbf{B})$ and potentiometry (C,D) from ChCl:Ethylene glycol (ethaline): (A) 0.01 M Sn (-1.25 V, 900 s, Cu substrate), B:0.01 M Sn $\left(-1.50 \mathrm{~V}, 900 \mathrm{~s}, \mathrm{Cu}\right.$ substrate), C: $0.01 \mathrm{M} \mathrm{Sn}\left(0.057 \mathrm{~A} / \mathrm{cm}^{2}, 900 \mathrm{~s}\right.$, Cu substrate), D: $0.01 \mathrm{M} \mathrm{Sn}\left(0.1142 \mathrm{~A} / \mathrm{cm}^{2}\right.$, $900 \mathrm{~s}, \mathrm{Cu}$ substrate). Images of $5 \mu \mathrm{m}$ scale with zoom in at $2 \mu \mathrm{m}$ scale.

The introduction of P-MWCNTs $(0.5 \mathrm{~g} / \mathrm{L}$, Figure 7$)$ changes the geometry of the particles; however, it is not possible to identify the presence of the carbon material. For the different studied parameters (A, B, and C), the particles present smaller size compared to Sn.
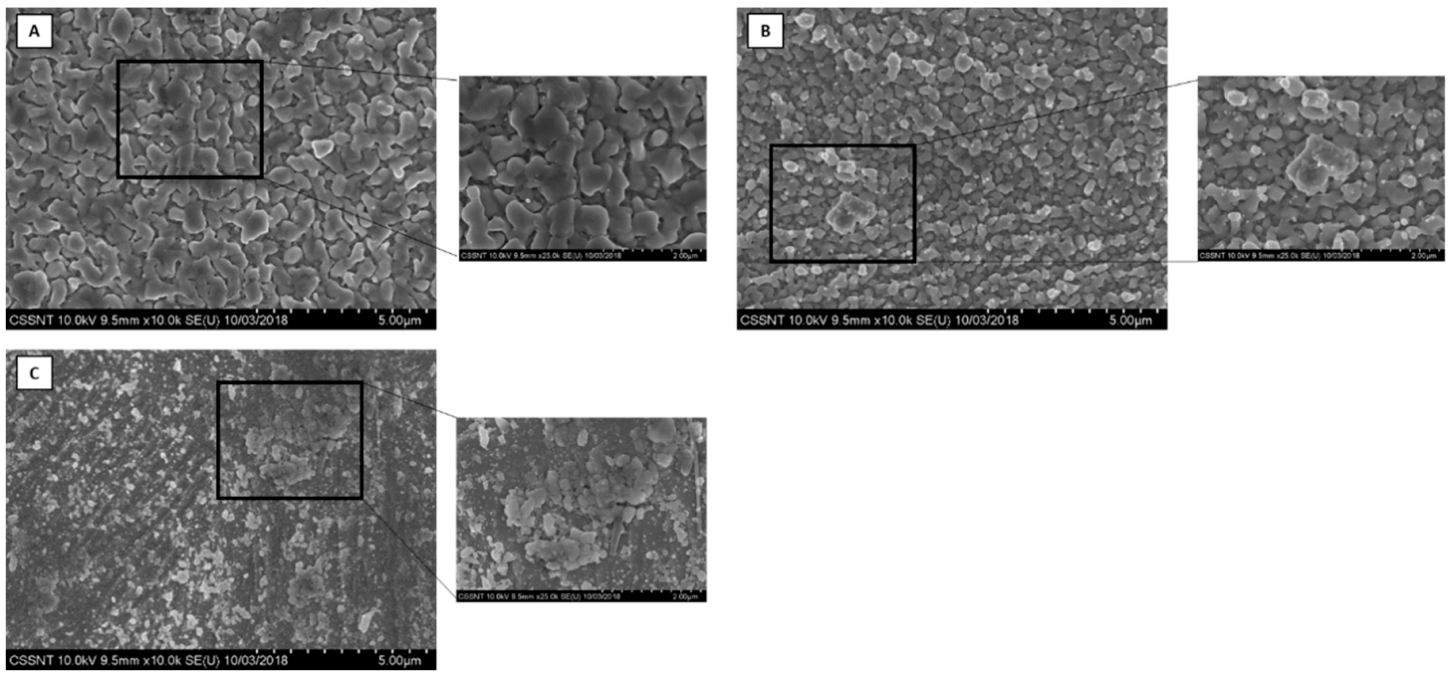

Figure 7. SEM images for Sn+ P-MWCNTs composite coatings prepared at $75^{\circ} \mathrm{C}$, by chronoamperometry (A,B) and potentiometry (C) from ChCl:Ethylene glycol (ethaline): (A) $0.01 \mathrm{MSn}$ (II)+ 0.5 g/L P-MWCNTs (-1.25 V, $900 \mathrm{~s}$, Cu substrate), B: $0.01 \mathrm{M} \mathrm{Sn}$ (II) + $0.5 \mathrm{~g} / \mathrm{L}$ P-MWCNTs (-1.50 V, $900 \mathrm{~s}$, Cu substrate), C: $0.01 \mathrm{M} \mathrm{Sn}$ (II) +0.5 (II) g/L P-MWCNTs $\left(0.057 \mathrm{~A} / \mathrm{cm}^{2}, 900 \mathrm{~s}\right.$, Cu substrate). Images of $5 \mu \mathrm{m}$ scale with zoom in at $2 \mu \mathrm{m}$ scale.

On the other hand, increasing the amount of P-MWCNTs ( $1 \mathrm{~g} / \mathrm{L}$, Figure 8$)$, it is clearly possible to identify the presence of CNTs. In Figure 8A $(-1.25 \mathrm{~V})$, the incorporation of the P-MWCNTs on the Sn matrix is clearly visible, with evidence of dendritic growth. Figure $8 \mathrm{~B}\left(0.1142 \mathrm{~A} / \mathrm{cm}^{2}\right)$ also shows the incorporation of P-MWCNTs. In this case, P-MWCNTs present in Figure $8 \mathrm{~B}$ present smaller diameter compared to Figure 8A. This may be due to the fact that in the first case, the Sn growth occurs on the P-MWCNTs surface as well. 

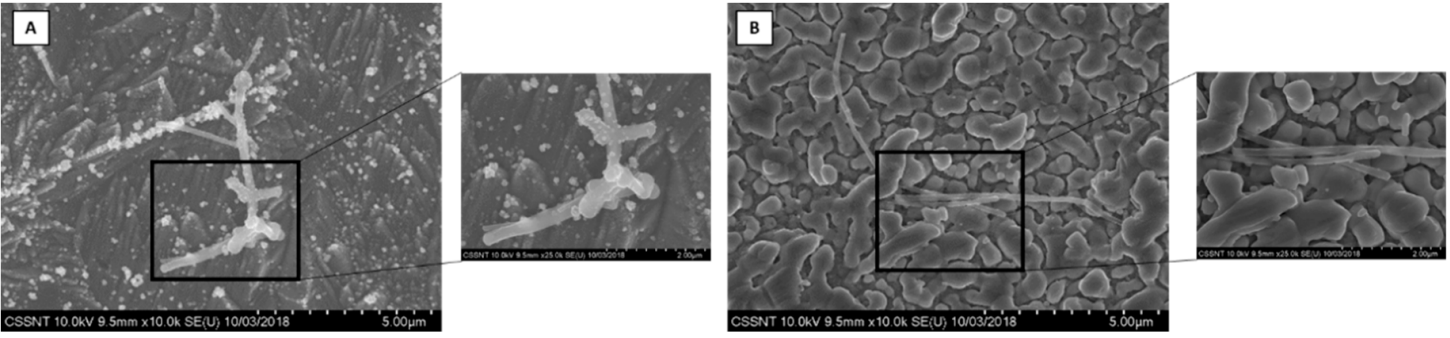

Figure 8. SEM images for Sn-P-MWCNTs composite coatings prepared at $75^{\circ} \mathrm{C}$, by chronoamperometry (A) and potentiometry (B) from ChCl:Ethylene glycol (ethaline): (A) $0.01 \mathrm{M} \mathrm{Sn}$ (II)+ $1 \mathrm{~g} / \mathrm{L} \mathrm{P-MWCNTs}$ (-1.25 V, $900 \mathrm{~s}$, Cu substrate), (B) $0.01 \mathrm{M} \mathrm{Sn}$ (II)+ $1 \mathrm{~g} / \mathrm{L}$ P-MWCNTs $\left(0.1142 \mathrm{~A} / \mathrm{cm}^{2}, 900 \mathrm{~s}\right.$, Cu substrate). Images of $5 \mu \mathrm{m}$ scale with zoom in at $2 \mu \mathrm{m}$ scale.

The oxidation of MWCNTs (Figure 9) shows the increase in the amount of CNTs present in the Sn matrix, indicating that the oxidation treatment can improve the incorporation of these carbon materials on the metal's matrix. The introduction of oxygen groups in the edges and walls of the MWCNTs leads to an increase of its hydrophilicity, making it easier to be incorporated inside the Sn matrix. In Figure 9A,C, the dendritic growth phenomenon is evidenced, with more emphasis in Figure 9C due to the fact that it is not possible to observe the presence of ox-MWCNTs.
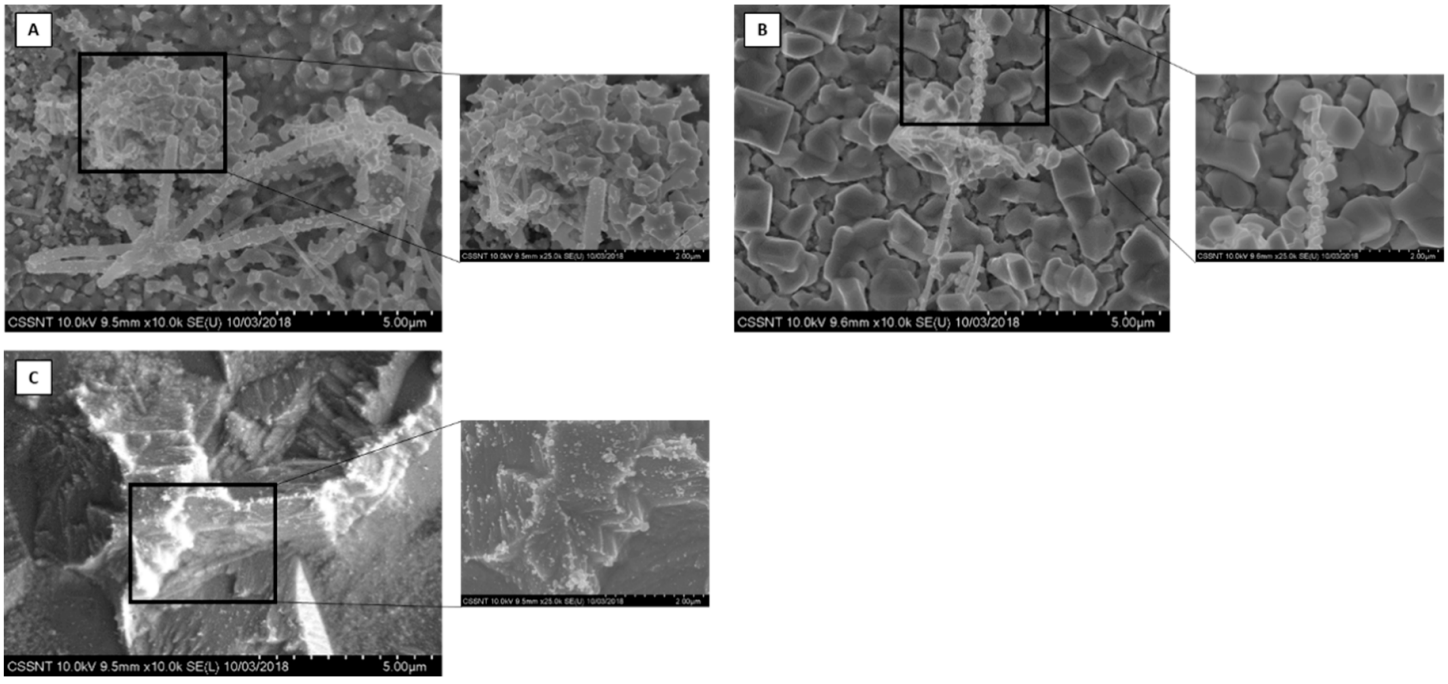

Figure 9. SEM images for Sn-ox-MWCNTs composite coatings prepared at $75{ }^{\circ} \mathrm{C}$, by chronoamperometry (A,B) and potentiometry (C) from ChCl:Ethylene glycol (ethaline): (A): $0.01 \mathrm{MSn}$ (II)+ $0.5 \mathrm{~g} / \mathrm{L}$ ox-MWCNTs (-1.25 V, 900 s, Cu substrate), (B): 0.01 M Sn (II)+ 0.5 g/L ox-MWCNTs (-1.50 V, $900 \mathrm{~s}$, Cu substrate), C: $0.01 \mathrm{M} \mathrm{Sn}$ (II)+ $0.5 \mathrm{~g} / \mathrm{L}$ ox-MWCNTs $\left(0.057 \mathrm{~A} / \mathrm{cm}^{2}, 900 \mathrm{~s}\right.$, Cu substrate). Images of $5 \mu \mathrm{m}$ scale with zoom in at $2 \mu \mathrm{m}$ scale.

Figure 10 presents the obtained morphology in the case of Sn-rGO composite coatings under potentiostatic (A) and galvanostatic (B) conditions, showing graphene inserted within the Sn matrix. The obtained deposit seems to exhibit a more compact structure, with quite uniform, spherical and smaller particles when a constant current density has been applied, i.e., $40 \mathrm{~mA} / \mathrm{cm}^{2}$. 




Figure 10. SEM images for Sn-rGO composite coatings prepared at $75{ }^{\circ} \mathrm{C}$, by chronoamperometry from ChCl:Ethylene glycol (ethaline): (A) $0.01 \mathrm{M} \mathrm{Sn}$ (II)+ $0.5 \mathrm{~g} / \mathrm{L} \mathrm{rGO} \mathrm{(-1.50} \mathrm{V,} 900 \mathrm{~s}$, Cu substrate), (B) $0.01 \mathrm{M} \mathrm{Sn}(\mathrm{II})+0.5 \mathrm{~g} / \mathrm{L} \mathrm{rGO}\left(0.04 \mathrm{~A} / \mathrm{cm}^{2}, 900 \mathrm{~s}\right.$, Cu substrate). Images of $5 \mu \mathrm{m}$ scale with zoom in at $1 \mu \mathrm{m}$ and $500 \mathrm{~nm}$ scale.

Figures 8 and 9 show the existence of dendritic structures. According to an early research by Cojocaru et al. [23], where Sn-Ni electrodeposition on DES-based choline chloride-urea was studied, they evidenced the dendritic shape of the metallic deposit. Anicai et al. [25] also studied Sn-Ni electrodeposition on DES-based choline chloride:ethylene glycol and choline chloride:malonic acid. They also evidenced particles with dendritic growth. According to Anicai et al. [25], this is due to the fact that at more negative potentials, the deposits are produced when the metals are reduced at the diffusion-limited rate. It has also been reported in the literature that voltage oscillations may be an indication of irregular growth of Sn deposits such as dendrites [60].

\subsection{XRD Studies}

Figure 11 presents the XRD patterns revealed by Sn and nano-carbon-based Sn composite coatings. As can be seen, the recorded diffraction peaks are notably sharp, suggesting a good crystallinity degree of the investigated samples.

The reflections observed for all the coatings around $30.61^{\circ}, 31.95^{\circ}, 44.86^{\circ}$, and $89.91^{\circ}$ 2theta angles, corresponding to 200,101, 211, and 501 crystallographic planes, respectively, are given by the presence of Sn phase, easily indexed to a tetragonal crystal system using the 00-004-0673 JCPDS reference card. The diffraction peaks which could be seen around $43.21^{\circ}, 50.48^{\circ}, 74.10^{\circ}$, and $95.12^{\circ}$ 2theta angles, assigned to 111, 200, 220, and 222 orientation planes, respectively, were attributed to the cubic crystal system $\mathrm{Cu}$ phase using the 01-070-3039 JCPDS reference card. The appearance of the $\mathrm{Cu}$ phase generated by the $\mathrm{Cu}$ substrates within the recorded diffractograms suggests that the prepared $\mathrm{Sn}$ and nano-carbon-based Sn coatings have small thicknesses, which are facilitating the penetration of the X-Rays into the substrate during analysis. This assumption is in good agreement with the thicknesses estimated using the weighing method.

In the XRD patterns exhibited by the carbon-based Sn composites, the presence of new diffraction peaks could be noticed at approximately $21.5^{\circ}$ and $27.5^{\circ} 2$ theta angles, indexed as 004 and 009 reflections of hexagonal graphite phase. Moreover, the reflection which appeared around $43.34^{\circ}$, attributed to the $\mathrm{Cu}$ phase, most likely, is overlapped/convoluted by the presence of 102 main orientation of the hexagonal carbon phase (00-026-1083 JCPDS reference card) as the intensity of this diffraction peak increases considerably after the addition of the carbon nanomaterials into the Sn matrix. Therefore, the presence of this peak confirms the successful incorporation of the nano-carbon materials into the metal. 


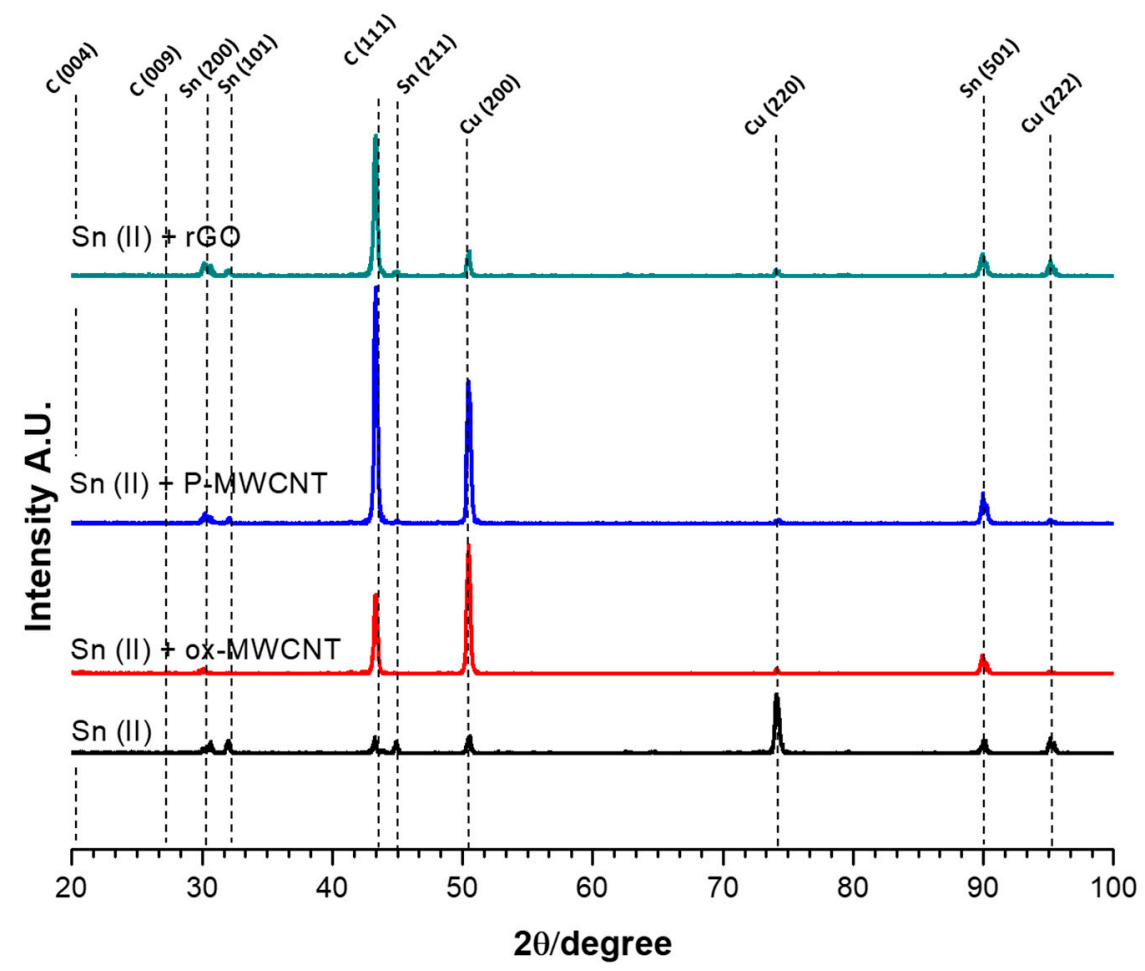

Figure 11. XRD diffractogram for $\mathrm{Sn}$ and $\mathrm{Sn}$-carbon material composite coatings from $\mathrm{ChCl:EG}$ containing $0.01 \mathrm{M}$ Sn (II) and $0.5 \mathrm{~g} / \mathrm{L}$ of carbon materials (deposits obtained by chronoamperometry with the following conditions: $-1.25 \mathrm{~V}, 600 \mathrm{~s}, \mathrm{~T}=75^{\circ} \mathrm{C}, \mathrm{Cu}$ substrate).

Based on the Scherrer equation, the crystallite size for the various indices of Sn and C are presented in Table 3, where for both elements, increasing the diffraction angle increases the crystallite size.

Table 3. Crystallite size determination from Scherrer equation for various index numbers.

\begin{tabular}{cccc}
\hline & $(\mathbf{h k l )}$ & $\left.\mathbf{2 \theta} \mathbf{(}^{\circ}\right)$ & $\boldsymbol{D}(\mathbf{n m})$ \\
\hline \multirow{4}{*}{ Sn } & 200 & 30.61 & 16.45 \\
\cline { 2 - 4 } & 101 & 31.95 & 16.63 \\
\cline { 2 - 4 } & 211 & 44.86 & 18.66 \\
\cline { 2 - 4 } & 501 & 89.91 & 23.64 \\
\hline \multirow{4}{*}{ Cu } & 111 & 43.21 & 17.86 \\
\cline { 2 - 4 } & 200 & 50.48 & 19.01 \\
\cline { 2 - 4 } & 220 & 74.10 & 21.78 \\
\cline { 2 - 4 } & 222 & 95.12 & 24.35 \\
\hline \multirow{3}{*}{$\mathbf{C}$} & 004 & 21.50 & 17.33 \\
\cline { 2 - 4 } & 009 & 27.50 & 19.21 \\
\cline { 2 - 4 } & 102 & 43.34 & 31.09 \\
\hline
\end{tabular}

\subsection{Raman Studies}

Raman spectroscopy is one of the most reliable techniques for the identification and characterization of CNTs. Figure 12 presents the Raman signal emitted by Sn composites, containing different amounts and types of nano-carbons, namely P-MWCNTs and ox-MWCNTs and rGO. 

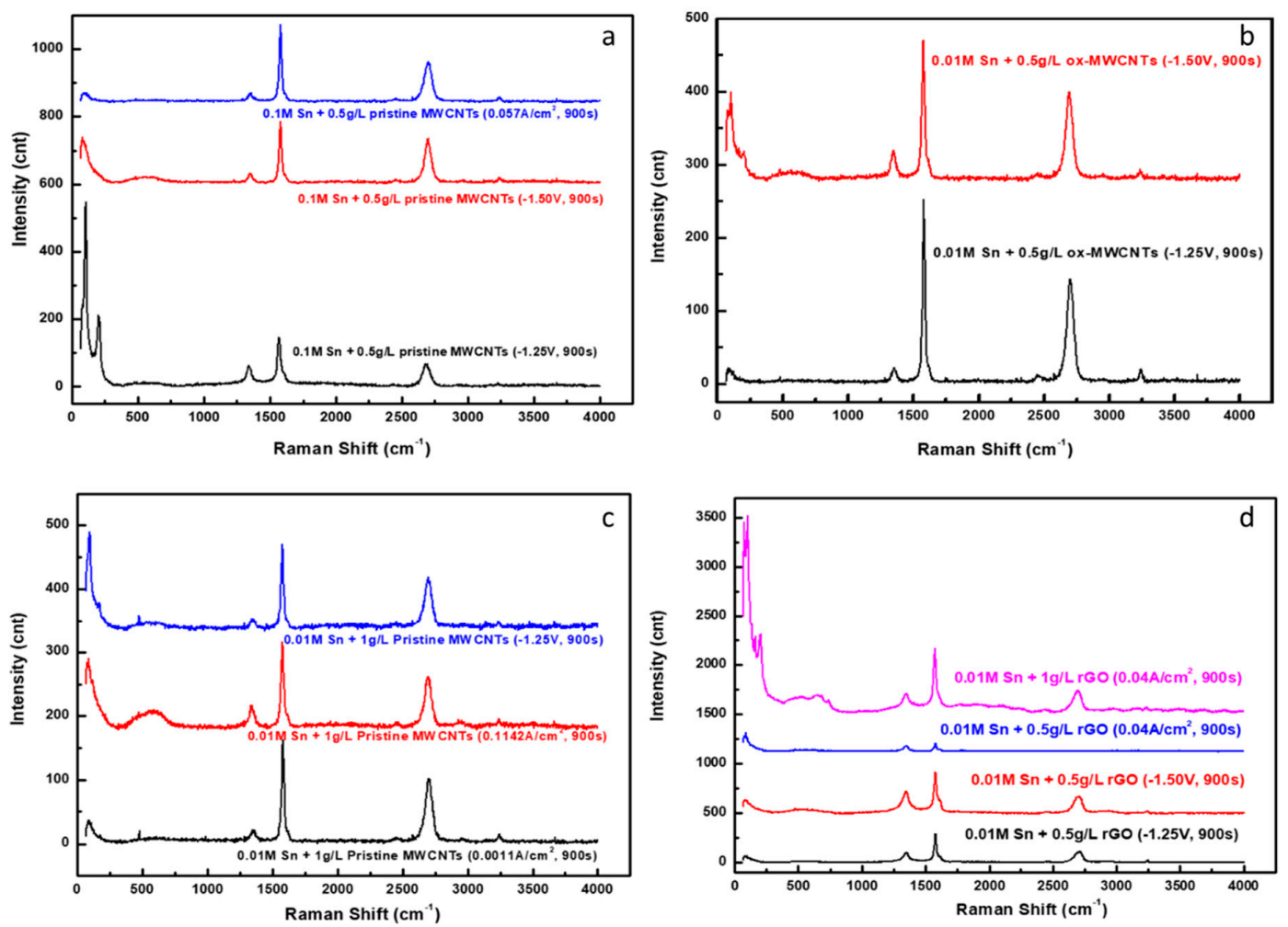

Figure 12. Raman spectra for Sn composite coatings from ChCl:EG containing Sn and MWCNTS and rGO materials ((a)—Sn (II) + 0.5 g/L P-MWCNTs; (b)—Sn (II) + ox-MWCNTs; (c)—Sn (II) + 1 g/L P-MWCNTs; (d)-Sn (II) +1 g/L rGO).

As can be observed, all the recorded Raman spectra exhibit the Raman signature of graphitic materials (MWCNTs and rGO), characterized by three principle peaks assigned to the first order D and $G$ modes, and to the second-order 2D mode. The $G$ band, which appears around $1580 \mathrm{~cm}^{-1}$, appears as a result of the in-plane stretching vibration of $C$ atoms. The $D$ band, which is revealed by the Raman spectra around $1350 \mathrm{~cm}^{-1}$, is attributed to disordered structures: defective CNT and non-crystalline carbon. Therefore, the presence of the D, G and 2D bands into the Raman spectra obtained for the investigated composites confirm the successful incorporation of the carbon nanomaterials into the $\mathrm{Sn}$ metallic matrix, as it was evidenced also by the XRD results.

The low frequency band, which appeared around $100 \mathrm{~cm}^{-1}$, could be attributed to the radial breathing mode (RBM) vibration of the thin innermost shell (diameter $<1 \mathrm{~nm}$ ) of the multi-wall carbon nanotubes [61,62]. Usually, this peak is attributed to the breathing mode of the SWCNT [63]. However, based on literature, this peak could also be assigned to tin oxide together with the broadened band around $550 \mathrm{~cm}^{-1}[64,65]$.

The $\mathrm{G}$ band, which appears around $1580 \mathrm{~cm}^{-1}$, indicates the degree of graphitization/ crystallinity. The $\mathrm{D}$ band, which is revealed by the Raman spectra around $1350 \mathrm{~cm}^{-1}$, is attributed to disordered structures: defective CNT and non-crystalline carbon. It reflects the lattice distortions in the tubes. Therefore, the crystallinity of carbonaceous materials can be determined using the intensity ratio denoted in the literature as ID/IG or as the integrated intensity ratio, AD/ AG (Table S1). For small disorder or perturbations, it is better to consider the area ratio, while for larger disorder it is more convenient to use the intensity ratio.

The ID/IG ratio for of $0.1 \mathrm{M} \mathrm{Sn}$ (II) + 0.5 g/L P-MWCNTs ( $-1.25 \mathrm{~V} ; 900 \mathrm{~s}$ ) (Figure 12a) is higher compared to of $0.1 \mathrm{M}$ Sn (II) $+0.5 \mathrm{~g} / \mathrm{L}$ P-MWCNTs $(-1.50 \mathrm{~V} ; 900 \mathrm{~s})$ (Figure 12a), which indicates an increase in the number of defects at a more positive applied voltage. However, in the case of ox/MWCNTs (Figure 12b, Figures S5 and S6), there are few variations in the ID/IG ratio with the applied voltage. 
In addition, the amount of P-MWCNTs (Figure 12a,c) seems to influence the number of defects. Samples from Figures S2 and S9 were prepared under the same conditions, but with different amounts of CNT. The ID/IG ratio is 0.21 and 0.08 for $1 \mathrm{~g} / \mathrm{L}$ of P-MWCNTs and $0.5 \mathrm{~g} / \mathrm{L}$ of P-MWCNTs, respectively.

The applied current density seems to influence the ID/IG ratio (Figure 12c, Figures S7 and S8). At higher current density, the ID/IG ratio is 0.14 , while at a lower current density, the ID/IG ratio is 0.03 . The values obtained from the ID/IG ratios are similar to those found in the literature [65].

The ID/IG ratios calculated for the rGO-based Sn coatings are higher (Figures S10-S13), compared to those containing CNTs. This indicates that the number of defects is greater in the case of rGO when compared to CNTs. For rGO, different voltages were applied and the values of the ID/IG ratios seem to indicate an increase in the number of defects when a more negative voltage is applied. On top of that, the amount of graphene oxide also influences this relationship. When it is increased, a decrease in the ratio of the intensities of $D$ and $G$ bands is observed.

\subsection{Corrosion Studies}

The protective nature of Sn and Sn composites was accessed by potentiodynamic polarization curves (not shown) and electrochemical impedance spectra (EIS), at open circuit potential (OCP) in $0.5 \mathrm{M} \mathrm{NaCl}$, for various immersion periods.

The recorded EIS plots and fitting for the Sn and Sn composites coatings, electrodeposited with different carbon materials dispersed in ethaline, are presented in Figure 13.
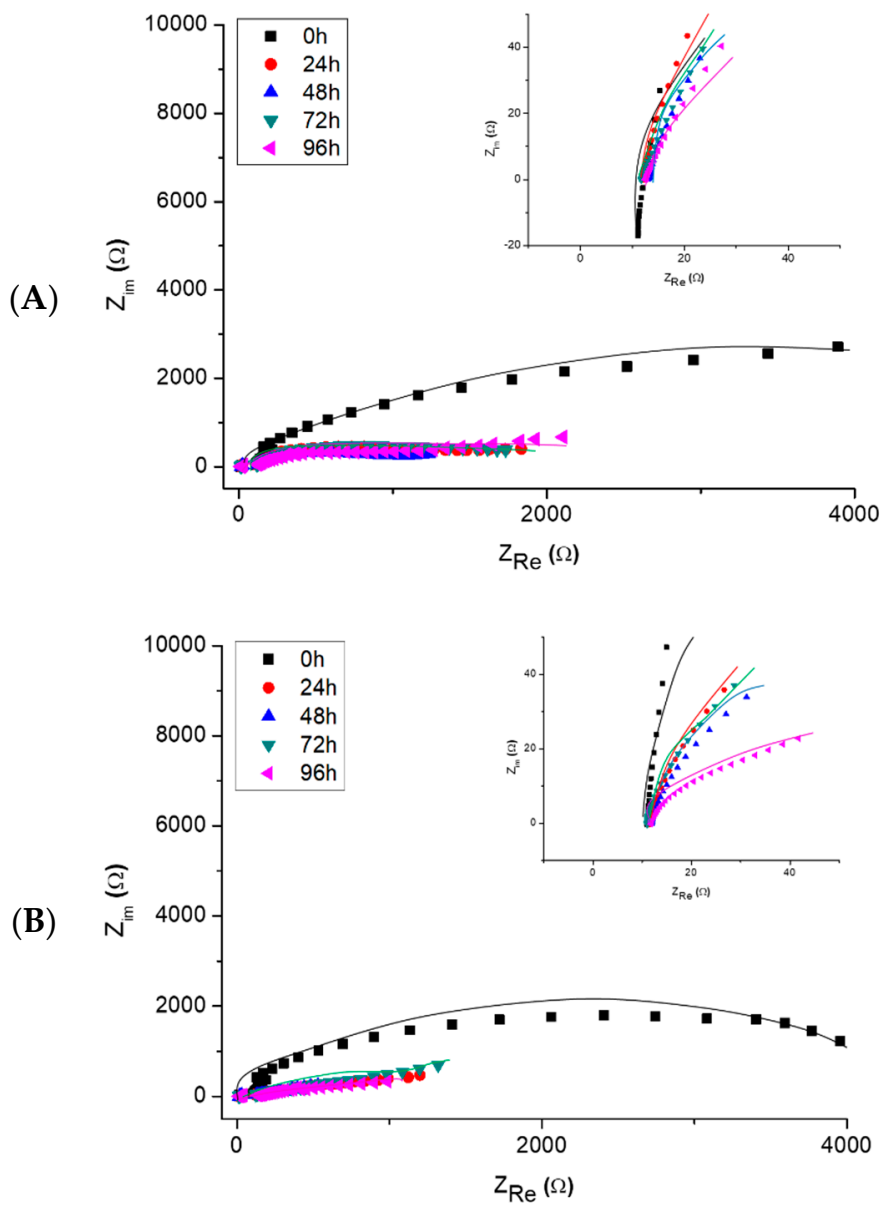

Figure 13. Cont. 

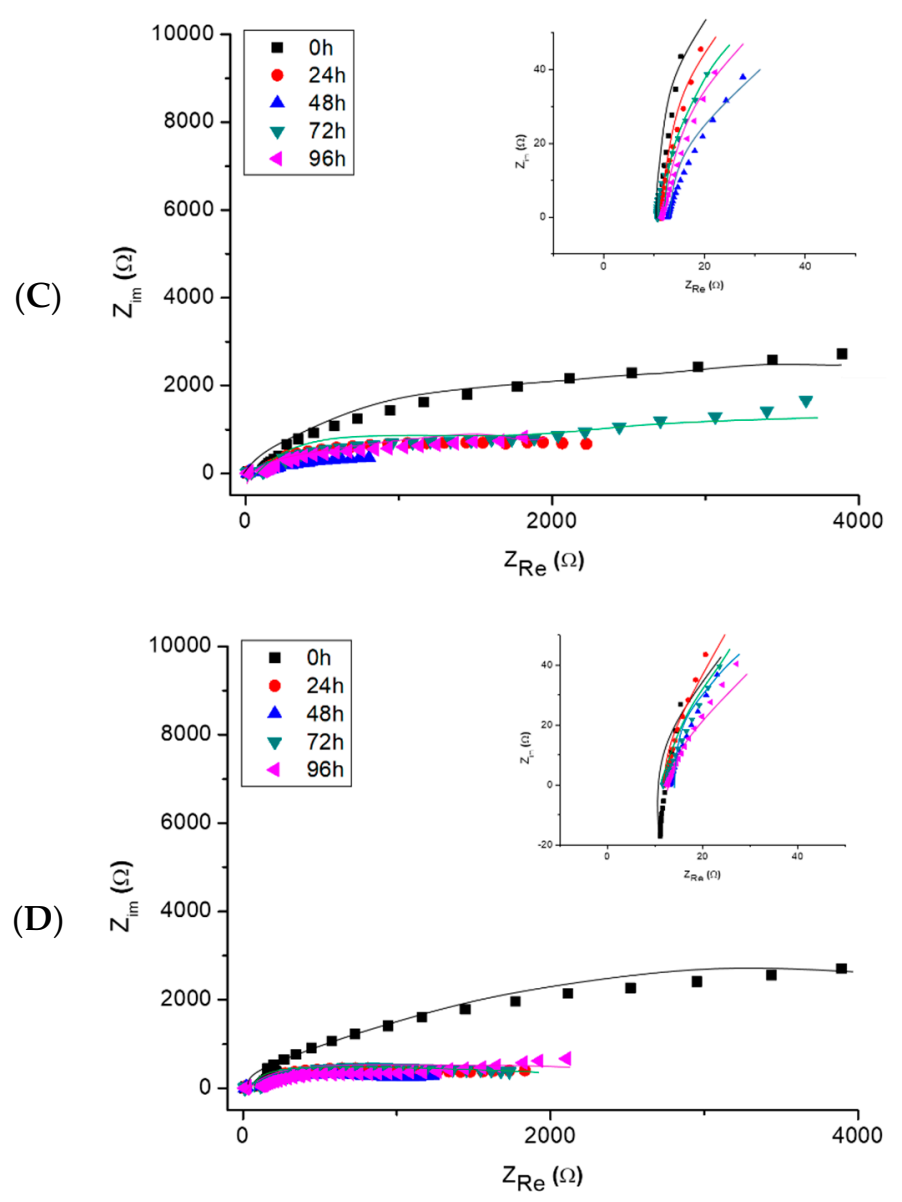

Figure 13. Nyquist plots and fitting in $0.5 \mathrm{M} \mathrm{NaCl}$ at $\mathrm{OCP}$, after different immersion times of Sn and Sn-carbon material composites ((A): Sn (II); (B): Sn (II) + ox-MWCNTs; (C): Sn (II) + P-MWCNTs; (D): $\mathrm{Sn}(\mathrm{II})+\mathrm{rGO})$ in ethaline. Inset with fitted high-frequency region.

The Nyquist plot evidences the presence of a single capacitive loop for all $\mathrm{Sn}$ and composites. The equivalent-circuit model proposed for the corrosion behavior of $\mathrm{Sn}$ and $\mathrm{Sn}$-composites in $0.5 \mathrm{M} \mathrm{NaCl}$ solution is presented in Figure 14. The corrosion process occurring in this case can be modeled with a R-CPE combination, including a CPE (Constant Phase Element-Q) in parallel with a charge-transfer resistor $\left(\mathrm{R}_{\mathrm{CT}}\right)$. $\mathrm{R}_{\mathrm{S}}$ corresponds to the solution ohmic resistance, and $\mathrm{CPE}$ is related to the double layer capacitance. CPE elements were used, instead of true capacitors due to the roughness of the metallic films [66]. The same circuit is applied for all the experiments, and the quality of the fitting was judged by the value of $\chi^{2}\left(<10^{-3}\right)$.

The values that present the best fit for the equivalent circuit $\left(R_{S}\right.$ and $\left.R_{C T}\right)$ for all $S n$ and composites are presented in Table 4.

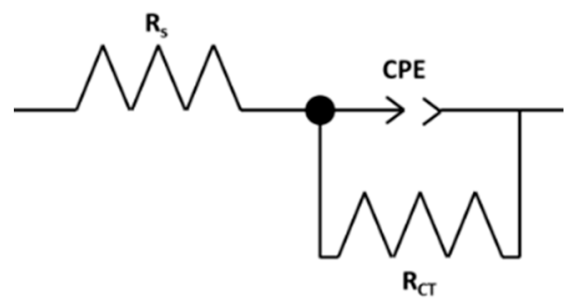

Figure 14. Equivalent-circuit proposed for the corrosion behavior of Sn deposits in $0.5 \mathrm{M} \mathrm{NaCl}$ solution. 
Table 4. Values for $\mathrm{R}_{\mathrm{S}}$ and $\mathrm{R}_{\mathrm{CT}}$ that fits best to the equivalent-circuit.

\begin{tabular}{|c|c|c|c|}
\hline Immersion Time/h & Coating Type & $\mathbf{R}_{\mathrm{S}} / \Omega$ & $\mathbf{R}_{\mathrm{CT}} / \Omega$ \\
\hline \multirow{4}{*}{$\mathbf{0}$} & Sn & 11.35 & $2.10 \times 10^{4}$ \\
\hline & Sn+ox-MWCNTs & 83.61 & $4.84 \times 10^{3}$ \\
\hline & Sn+P-MWCNTs & 60.69 & $1.56 \times 10^{4}$ \\
\hline & $\mathrm{Sn}+\mathrm{rGO}$ & 57.51 & $8.45 \times 10^{3}$ \\
\hline \multirow{4}{*}{24} & Sn & 32.12 & $3.48 \times 10^{3}$ \\
\hline & Sn+ox-MWCNTs & 54.23 & $3.30 \times 10^{3}$ \\
\hline & Sn+P-MWCNTs & 70.30 & $2.55 \times 10^{3}$ \\
\hline & $\mathrm{Sn}+\mathrm{rGO}$ & 56.13 & $2.19 \times 10^{3}$ \\
\hline \multirow{4}{*}{48} & Sn & 44.23 & $3.24 \times 10^{3}$ \\
\hline & Sn+ox-MWCNTs & 33.45 & $2.31 \times 10^{3}$ \\
\hline & Sn+P-MWCNTs & 91.61 & $2.25 \times 10^{3}$ \\
\hline & $\mathrm{Sn}+\mathrm{rGO}$ & 96.72 & $9.58 \times 10^{2}$ \\
\hline \multirow{4}{*}{72} & Sn & 53.43 & $3.15 \times 10^{3}$ \\
\hline & Sn+ox-MWCNTs & 55.38 & $3.43 \times 10^{3}$ \\
\hline & Sn+P-MWCNTs & 90.12 & $2.01 \times 10^{3}$ \\
\hline & $\mathrm{Sn}+\mathrm{rGO}$ & 98.57 & $1.35 \times 10^{3}$ \\
\hline \multirow{4}{*}{96} & Sn & 72.90 & $3.29 \times 10^{3}$ \\
\hline & Sn+ox-MWCNTs & 99.82 & $1.55 \times 10^{3}$ \\
\hline & Sn+P-MWCNTs & 82.84 & $2.55 \times 10^{3}$ \\
\hline & $\mathrm{Sn}+\mathrm{rGO}$ & 6.17 & $4.71 \times 10^{3}$ \\
\hline
\end{tabular}

According to the fitting results, for $S n$ film the value of $R_{C T}$ decreased drastically from $t=0 \mathrm{~h}$ to $t=24 \mathrm{~h}$, remaining almost constant throughout the time of immersion, suggesting the formation of a protective passive film on the surface. The same behavior was observed for $\mathrm{Sn}+\mathrm{P}$-MWCNTs composites, presenting lower values of $\mathrm{R}_{\mathrm{CT}}$ after $24 \mathrm{~h}$. Sn + rGO composite present less stable behavior. The most stable behavior is attributed to $\mathrm{Sn}+$ ox-MWCNTs composite. Even though this system presents low value of resistance for $t=0 \mathrm{~h}$, the variation through time is almost negligible, presenting a slight increase at $\mathrm{t}=72 \mathrm{~h}$, indicating that a passive film was formed on the deposit's surface during the immersion period.

Polarization resistance values for pure Sn deposits gradually decreases throughout time. However, after $96 \mathrm{~h}$ there is a slight increase, suggesting an increase in the protective behavior of the deposit.

In the case of Sn+ ox-MWCNTs composite coatings, there is a similar behavior; however, the resistance values are slightly lower when compared to pure $\mathrm{Sn}$. There is a considerable increase of resistance at $72 \mathrm{~h}$ that might indicate that the presence of ox-MWCNTs, which may interfere in the formation of a passive layer, preventing the diffusion of the $\mathrm{Cl}$ - ions through the film.

For the initial time of immersion, Sn+P-MWCNTs present the best resistance value, but after $24 \mathrm{~h}$ show a substantial decrease, remaining almost constant throughout the time.

The presence of rGO seems to decrease the ability of resistance of the deposit after $48 \mathrm{~h}$; however, the resistance increases with increasing time.

At the initial time of immersion, Sn+P-MWCNTs seems to have the best corrosion behavior, followed by $\mathrm{Sn}+$ ox-MWCNTs, pure $\mathrm{Sn}$ and $\mathrm{Sn}+\mathrm{rGO}$; however, at $96 \mathrm{~h}, \mathrm{Sn}+\mathrm{rGO}$ presents the best behavior, indicating that $\mathrm{rGO}$ might lead to an increase in protection against corrosion.

Figure 15 presents the variation of the OCP as a function of the time during the immersion test. 


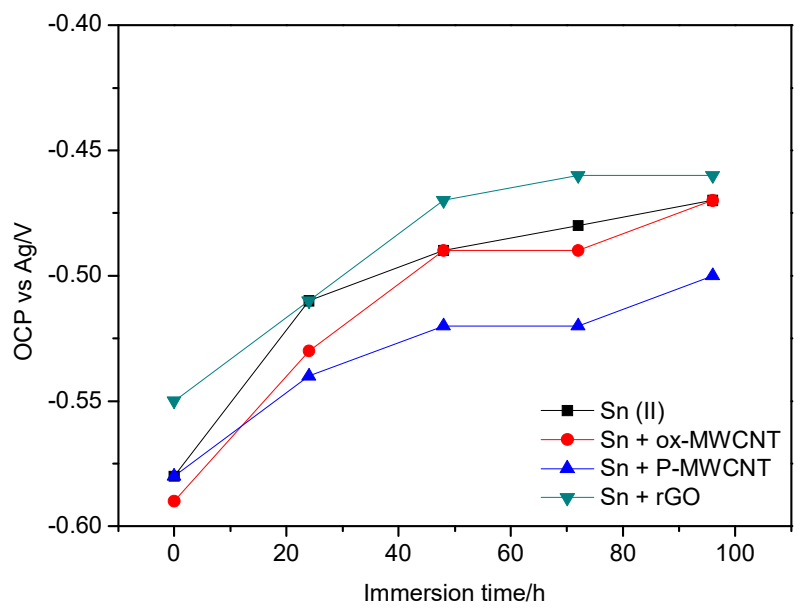

Figure 15. Time dependence of the OCP for the different Sn composites.

There is a visible displacement of the OCP towards positive values, mostly in the first 24/48 $\mathrm{h}$ of exposure, for all investigated composites, then, the OCP values tends to stabilize which seems to indicate a good performance of all the composites in terms of corrosion protection. The higher values of OCP are associated to $\mathrm{Sn}+\mathrm{rGO}$ composite, suggesting a slightly better corrosion performance, also supported by the values presented in Table 4 .

\section{Conclusions}

The current investigations proved that the electrodeposition of Sn and Sn-carbon materials composites can be successfully performed using a $\mathrm{ChCl}$ :EG eutectic mixture. All carbon nanomaterials studied showed an excellent level of dispersion in the ChCl:EG eutectic mixture containing Sn (II) ions, allowing its incorporation in the Sn matrix and having a good adherence to the $\mathrm{Cu}$ substrate.

Chronoamperometric analysis show that $\mathrm{Sn}$ and $\mathrm{Sn}$ composites nucleation on a GC surface occurs through a 3D instantaneous process with growth controlled by diffusion. The number of active sites increases when the potential becomes more cathodic and the values of the nucleation rate present higher values for pure $\mathrm{Sn}$, when compared to the samples with MWCNTs and rGO.

AFM images show that the introduction of carbon materials decreases the conductivity of the surface, with the exception of ox-MWCNTs, which present a slightly higher conductivity, when compared to pure Sn.

SEM images show that MWCNTs and rGO can be successfully incorporated in the Sn matrix. Raman and XRD analysis also confirmed the presence of MWCNTs and rGO on the Sn matrix.

Corrosion tests indicated that the introduction of carbon materials in the Sn matrix did not promote a substantial increase in the corrosion protection; however, better performance at long exposure is presented by the $\mathrm{Sn}+\mathrm{rGO}$ composite, compared to pure Sn. Further studies will try to get more information regarding their protective characteristics including the preparation and assessment of thicker coatings which should be more appropriate for use in real industrial applications.

Supplementary Materials: The following are available online at http://www.mdpi.com/2079-6412/9/12/798/s1, Figure S1 Dimensionless plot of $\left(i / i_{\max }\right) 2$ vs. $t / t_{\max }$ for $S n$ and composites (chronoamperometry parameters: step potential: $-0.550 \mathrm{~V})$, Figure S2 Raman spectrum and deconvolution of $0.1 \mathrm{M} \mathrm{Sn}$ (II) + 0.5 g/L P-MWCNTs ( $-1.25 \mathrm{~V}$; $900 \mathrm{~s}$ ) sample, Figure S3 Raman spectrum and deconvolution of $0.1 \mathrm{M}$ Sn (II) + 0.5 g/L P-MWCNTs ( -1.50 V; 900 s) sample, Figure S4 Raman spectrum and deconvolution of 0.1 M Sn (II) + 0.5 g/L P-MWCNTs ( 0.057 A/cm²; $900 \mathrm{~s})$ sample, Figure S5 Raman spectrum and deconvolution of $0.01 \mathrm{M}$ Sn (II) + 0.5 g/L ox-MWCNTs (-1.25 V; 900 s) sample, Figure S6 Raman spectrum and deconvolution of $0.01 \mathrm{M}$ Sn (II) + 0.5 g/L ox-MWCNTs (-1.50 V; $900 \mathrm{~s})$ sample, Figure 57 Raman spectrum and deconvolution of $0.01 \mathrm{M}$ Sn (II) $+1 \mathrm{~g} / \mathrm{L} \mathrm{P-MWCNTs}\left(0.0011 \mathrm{~A} / \mathrm{cm}^{2}\right.$; $900 \mathrm{~s})$ sample, Figure S8 Raman spectrum and deconvolution of $0.01 \mathrm{M} \mathrm{Sn}$ (II) + $1 \mathrm{~g} / \mathrm{L} \mathrm{P-MWCNTs}\left(0.1142 \mathrm{~A} / \mathrm{cm}^{2}\right.$; $900 \mathrm{~s})$ sample, Figure S9 Raman spectrum and deconvolution of $0.01 \mathrm{M}$ Sn (II) + $1 \mathrm{~g} / \mathrm{L}$ P-MWCNTs (-1.25 V; $900 \mathrm{~s}$ ) sample, Figure S10 Raman spectrum and deconvolution of $0.01 \mathrm{M}$ Sn (II) + 0.5 g/L rGO (-1.25 V; $900 \mathrm{~s})$ sample, Figure S11 Raman spectrum and deconvolution of $0.01 \mathrm{M} \mathrm{Sn}$ (II) + 0.5 g/L rGO (-1.50 V; $900 \mathrm{~s})$ sample, Figure S12 
Raman spectrum and deconvolution of 0.01 M Sn (II) + 0.5 g/L rGO (0.04 A/cm²; $900 \mathrm{~s})$ sample, Figure S13 Raman spectrum and deconvolution of $0.01 \mathrm{M} \mathrm{Sn}(\mathrm{II})+1 \mathrm{~g} / \mathrm{L} \mathrm{rGO}\left(0.04 \mathrm{~A} / \mathrm{cm}^{2} ; 900 \mathrm{~s}\right)$ sample, Table S1 The ID/IG and $\mathrm{AD} / \mathrm{AG}$ ratios calculated for all samples.

Author Contributions: A.T.S.C.B.: experimental analysis, writing of the original draft, investigation; L.A.: writing-review and editing: C.M.P.: supervision, writing-review and editing; O.A.L.: SEM and Raman analysis; S.R.: Raman analysis; A.P.: Raman analysis; M.E.: SEM and Raman resources and discussion; R.C.: Carbon nanomaterials preparation; A.F.S.: Supervision;

Funding: This research was funded by NOVTINALBEST project (contract number M-ERA.NET/0009/2012). Part of the work has been also funded by ROFCC project, Contract No. 25 PCCDI/2018.

Acknowledgments: The authors would like to thank to:

- $\quad$ FCT under Research Grant QUI/UI0081/2019—CIQUP

- IL4Energy project (02/SAICT/2017 funded by FCT and the European Funds for regional development (FEDER) through the operational program of competitiveness and internationalization with reference POCI-01-0145-FEDER-032294)

- $\quad$ COST Action CA15107-MULTICOMP (MULTI-FUNCTIONAL NANO-CARBON COMPOSITE MATERIALS NETWORK)

- Ana Brandão would like to thank SCANSCI-equipamentos de laboratório for the financial support given to the PhD program and to ILs4Energy project a research grant.

- $\quad$ Renata Costa acknowledges a Post-Doc scholarship awarded by FCT with reference SFRH/BPD/89752/2012.

Conflicts of Interest: The authors declare no conflict of interest.

\section{References}

1. Yang, K.K.; Mahmoudian, M.R.; Ebadi, M.; Koay, H.L.; Basirun, W.J. Diffusion coefficient of tin(II) methanesulfonate in ionic liquid and methane sulfonic acid (MSA) solvent. Metall. Mater. Trans. B 2011, 42, 1274-1279. [CrossRef]

2. Walsh, F.C.; Low, C.T.J. A review of developments in the electrodeposition of tin. Surf. Coat. Technol. 2016, 288, 79-94. [CrossRef]

3. Habboush, D.A.; Osteryoung, R.A. Electrochemical studies of antimony(III) and antimony(V) in molten mixtures of aluminum chloride and butylpyridinium chloride. Inorg. Chem. 1984, 23, 1726-1734. [CrossRef]

4. López-León, S.; Ortega-Borges, R.; Brisard, G. Nickel electrodeposition from protic ionic liquids based on carboxylate anions as electrolyte: II. electrodeposition from 2-hydroxyethyl ammonium propionate. Int. J. Electrochem. Sci. 2013, 8, 1382-1393.

5. Abbott, A.P.; Capper, G.; McKenzie, K.J.; Ryder, K.S. Electrodeposition of zinc-tin alloys from deep eutectic solvents based on choline chloride. J. Electroanal. Chem. 2007, 599, 288-294. [CrossRef]

6. Abbott, A.P.; Capper, G.; Davies, D.L.; Munro, H.L.; Rasheed, R.K.; Tambyrajah, V. Preparation of novel, moisture-stable, Lewis-acidic ionic liquids containing quaternary ammonium salts with functional side chains. Chem. Commun. 2001, 19, 2010-2011. [CrossRef]

7. Endres, F.; MacFarlane, D.R.; Abbott, A.P. Electrodeposition from Ionic Liquids; Wiley-VCH Verlag GmbH \& Co.: Weinheim, Germany, 2008; ISBN 9783527312399.

8. Abbott, A.P.P.; El Ttaib, K.; Ryder, K.S.S.; Smith, E.L.L. Electrodeposition of nickel using eutectic based ionic liquids. Trans. IMF 2008, 86, 234-240. [CrossRef]

9. Abbott, A.P.; Ballantyne, A.; Harris, R.C.; Juma, J.A.; Ryder, K.S.; Forrest, G. A Comparative Study of Nickel Electrodeposition Using Deep Eutectic Solvents and Aqueous Solutions. Electrochim. Acta 2015, 176, 718-726. [CrossRef]

10. Abbott, A.P.; Nandhra, S.; Postlethwaite, S.; Smith, E.L.; Ryder, K.S. Electroless deposition of metallic silver from a choline chloride-based ionic liquid: A study using acoustic impedance spectroscopy. Phys. Chem. Chem. Phys. 2007, 9, 3735-3743. [CrossRef]

11. Anicai, L.; Florea, A.; Visan, T. Studies Regarding the Nickel Electrodeposition from Choline Chloride Based Ionic Liquids. Appl. Ion. Liq. Sci. Technol. 2011, 13, 261-286.

12. Anicai, L.; Costovici, S.; Cojocaru, A.; Manea, A.; Visan, T. Electrodeposition of Co and CoMo alloys coatings using choline chloride based ionic liquids-evaluation of corrosion behaviour. Trans. Inst. Met. Finish. 2015, 93, 302-312. [CrossRef] 
13. Lee, Y.R.; Row, K.H. Comparison of ionic liquids and deep eutectic solvents as additives for the ultrasonic extraction of astaxanthin from marine plants. J. Ind. Eng. Chem. 2016, 39, 87-92. [CrossRef]

14. Khandelwal, S.; Tailor, Y.K.; Kumar, M. Deep eutectic solvents (DESs) as eco-friendly and sustainable solvent/catalyst systems in organic transformations. J. Mol. Liq. 2016, 215, 345-386. [CrossRef]

15. Chen, Z.; Ludwig, M.; Warr, G.G.; Atkin, R. Effect of cation alkyl chain length on surface forces and physical properties in deep eutectic solvents. J. Colloid Interface Sci. 2017, 494, 373-379. [CrossRef]

16. Abbott, A.P.; Barron, J.C.; Frisch, G.; Gurman, S.; Ryder, K.S. Fernando Silva, a Double layer effects on metal nucleation in deep eutectic solvents. Phys. Chem. Chem. Phys. 2011, 13, 10224-10231. [CrossRef]

17. Abbott, A.P.; Barron, J.C.; Frisch, G.; Ryder, K.S.; Silva, A.F. The effect of additives on zinc electrodeposition from deep eutectic solvents. Electrochim. Acta 2011, 56, 5272-5279. [CrossRef]

18. Al Kiey, S.A.; El-Warraky, A.A.; Abdel Rehim, S.S.; Zein El Abedin, S. Template-assisted electrodeposition of freestanding sn, in and sn-in nanowire arrays in an ionic liquid. Egypt. J. Chem. 2019, 62, 965-971. [CrossRef]

19. Xie, X.; Zou, X.; Zheng, K.; Wang, S.; Lu, X.; Xu, Q.; Zhou, Z. Ionic liquids electrodeposition of Sn with different structures as anodes for lithium-ion batteries. J. Electrochem. Soc. 2017, 164, D945-D953. [CrossRef]

20. Jie, S.; Ting-yun, M.; Hui-xuan, Q.; Qi-song, L. Preparation of black Cu-Sn alloy with single phase composition by electrodeposition method in 1-butyl-3-methylimidazolium chloride ionic liquids. Mater. Chem. Phys. 2018, 219, 421-424. [CrossRef]

21. Xu, X.H.; Hussey, C.L. The Electrochemistry of Tin in the Aluminum Chloride-1-Methyl-3-Ethylimidazolium Chloride Molten Salt. J. Electrochem. Soc. 1993, 140, 618-626.

22. Tachikawa, N.; Serizawa, N.; Katayama, Y.; Miura, T. Electrochemistry of Sn(II)/Sn in a hydrophobic room-temperature ionic liquid. Electrochim. Acta 2008, 53, 6530-6534.

23. Cojocaru, A.; Costovici, Ş.; Anicǎi, L.; Vişan, T. Studies of cathodic processes during nisn alloy deposition using choline chloride based ionic liquids. Metal. Int. 2009, 14, 38-46.

24. Salomé, S.; Pereira, N.M.; Ferreira, E.S.; Pereira, C.M.; Silva, A.F. Tin electrodeposition from choline chloride based solvent: Influence of the hydrogen bond donors. J. Electroanal. Chem. 2013, 703, 80-87.

25. Anicai, L.; Petica, A.; Costovici, S.; Prioteasa, P.; Visan, T. Electrodeposition of Sn and NiSn alloys coatings using choline chloride based ionic liquids-Evaluation of corrosion behavior. Electrochim. Acta 2013, 114, 868-877. [CrossRef]

26. Wang, L.; Pumera, M. Electrochemical catalysis at low dimensional carbons: Graphene, carbon nanotubes and beyond-A review. Appl. Mater. Today 2016, 5, 134-141. [CrossRef]

27. Stobinski, L.; Lesiak, B.; Kövér, L.; Tóth, J.; Biniak, S.; Trykowski, G.; Judek, J. Multiwall carbon nanotubes purification and oxidation by nitric acid studied by the FTIR and electron spectroscopy methods. J. Alloys Compd. 2010, 501, 77-84. [CrossRef]

28. Iijima, S. Helical microtubules of graphitic carbon. Nature 1991, 354, 56. [CrossRef]

29. Corry, B. Designing carbon nanotube membranes for efficient water desalination. J. Phys. Chem. B 2008, 112, 1427-1434. [CrossRef]

30. Rahman, G.; Najaf, Z.; Mehmood, A.; Bilal, S.; Shah, A.; Mian, S.; Ali, G. An Overview of the Recent Progress in the Synthesis and Applications of Carbon Nanotubes. C J. Carbon Res. 2019, 5, 3.

31. Martis, P.; Dilimon, V.S.; Delhalle, J.; Mekhalif, Z. Impact of surface functionalization of MWCNTs on electrogenerated Ni/MWCNT composites from aqueous solutions. Mater. Chem. Phys. 2011, 128, 133-140.

32. Rashad, M.; Pan, F.; Asif, M.; Li, L. Enhanced ductility of Mg-3Al-1Zn alloy reinforced with short length multi-walled carbon nanotubes using a powder metallurgy method. Prog. Nat. Sci. Mater. Int. 2015, 25, 276-281. [CrossRef]

33. Sanati, A.L.; Karimi-Maleh, H.; Badiei, A.; Biparva, P.; Ensafi, A.A. A voltammetric sensor based on NiO/CNTs ionic liquid carbon paste electrode for determination of morphine in the presence of diclofenac. Mater. Sci. Eng. C 2014, 35, 379-385. [CrossRef] [PubMed]

34. Zhao, J.; Liu, P.; Yang, Z.; Zhou, P.; Zhang, Y. One-Step Cutting of Multi-Walled Carbon Nano-tubes Using Nanoscissors Citation. Nano-Micro Lett. 2011, 3, 86-90. [CrossRef]

35. Arai, S.; Osaki, T.; Hirota, M.; Uejima, M. Fabrication of copper/single-walled carbon nanotube composite film with homogeneously dispersed nanotubes by electroless deposition. Mater. Today Commun. 2016, 7, 101-107. [CrossRef]

36. Praveen, B.M.; Venkatesha, T.V. Electrodeposition and properties of Zn-Ni-CNT composite coatings. J. Alloys Compd. 2009, 482, 53-57. [CrossRef] 
37. Bakshi, S.R.; Lahiri, D.; Agarwal, A. Carbon nanotube reinforced metal matrix composites-A review. Int. Mater. Rev. 2010, 55, 41-64. [CrossRef]

38. Alishahi, M.; Saatchi, A. The Effect of the Carbon Nanotube Content on the Corrosion Behaviour of Ni-P-CNT Composite Coating. Int. J. Iron Steel Soc. Iran 2012, 9, 1-5.

39. Yoshio, M.; Brodd, R.J.; Kozawa, A. Lithium-Ion Batteries; Springer: New York, NY, USA, 2009; Volume 1, pp. 140-149.

40. Mauger, A.; Xie, H.M.; Julien, C. Composite anodes for lithium-ion batteries: Status and trends. AIMS Mater. Sci. 2016, 3, 1054-1106. [CrossRef]

41. Xin, X.; Zhou, X.; Wang, F.; Yao, X.; Xu, X.; Zhu, Y.; Liu, Z. A 3D porous architecture of Si/graphene nanocomposite as high-performance anode materials for Li-ion batteries. J. Mater. Chem. 2012, 22, 7724. [CrossRef]

42. Hernandez, D.; Mendoza, F.; Febus, E.; Weiner, B.R.; Morell, G. Binder Free SnO 2-CNT Composite as Anode Material for Li-Ion Battery. J. Nanotechnol. 2014, 2014, 381273. [CrossRef]

43. Xu, Y.; Zhu, Y.; Liu, Y.; Wang, C. Electrochemical performance of porous carbon/tin composite anodes for sodium-ion and lithium-ion batteries. Adv. Energy Mater. 2013, 3, 128-133. [CrossRef]

44. Park, M.S.; Needham, S.A.; Wang, G.X.; Kang, Y.M.; Park, J.S.; Dou, S.X.; Liu, H.K. Nanostructured $\mathrm{SnSb} /$ carbon nanotube composites synthesized by reductive precipitation for lithium-ion batteries. Chem. Mater. 2007, 19, 2406-2410. [CrossRef]

45. Martis, P.; Dilimon, V.S.; Delhalle, J.; Mekhalif, Z. Electrochimica Acta Electro-generated nickel / carbon nanotube composites in ionic liquid. Electrochim. Acta 2010, 55, 5407-5410. [CrossRef]

46. Pereira, N.M.; Brincoveanu, O.; Pantazi, A.G.; Pereira, C.M.; Araújo, J.P.; Fernando Silva, A.; Enachescu, M.; Anicai, L. Electrodeposition of Co and Co composites with carbon nanotubes using choline chloride-based ionic liquids. Surf. Coat. Technol. 2017, 324, 451-462. [CrossRef]

47. Das, R.; Hamid, S.; Ali, M.; Ramakrishna, S.; Yongzhi, W. Carbon Nanotubes Characterization by X-ray Powder Diffraction-A Review. Curr. Nanosci. 2014, 11, 23-35. [CrossRef]

48. Silva, A.M.T.; Machado, B.F.; Figueiredo, J.L.; Faria, J.L. Controlling the surface chemistry of carbon xerogels using HNO3-hydrothermal oxidation. Carbon N. Y. 2009, 47, 1670-1679. [CrossRef]

49. Hummers, W.S.; Offeman, R.E. Preparation of Graphitic Oxide. J. Am. Chem. Soc. 1958, 80, 1339. [CrossRef]

50. Park, S.; An, J.; Potts, J.R.; Velamakanni, A.; Murali, S.; Ruoff, R.S. Hydrazine-reduction of graphite- and graphene oxide. Carbon N. Y. 2011, 49, 3019-3023. [CrossRef]

51. Milchev, A.; Michailova, E.; Lesigiarska, I. Spatial distribution of active sites on a glassy carbon surface. Electrochem. Commun. 2000, 2, 407-411. [CrossRef]

52. Scharifker, B.; Hills, G. Theoretical and experimental studies of multiple nucleation. Electrochim. Acta 1983, 28, 879-889. [CrossRef]

53. Grujicic, D.; Pesic, B. Electrodeposition of copper: The nucleation mechanisms. Electrochim. Acta 2002, 47, 2901-2912. [CrossRef]

54. Sebastián, P.; Vallés, E.; Gómez, E. First stages of silver electrodeposition in a deep eutectic solvent. Comparative behavior in aqueous medium. Electrochim. Acta 2013, 112, 149-158. [CrossRef]

55. Deng, M.-J.; Lin, P.-C.; Chang, J.-K.; Chen, J.-M.; Lu, K.-T. Electrochemistry of Zn(II)/Zn on Mg alloy from the N-butyl-N-methylpyrrolidinium dicyanamide ionic liquid. Electrochim. Acta 2011, 56, 6071-6077. [CrossRef]

56. Trejo, G.; Ortega, B.R.; Mecis, V.Y.; Ozil, P.; Chainet, E.; Nguyen, B. Nucleation and Growth of Zinc from Chloride Concentrated Solutions. J. Electrochem. Soc. 1998, 145, 4090-4097. [CrossRef]

57. Sebastián, P.; Botello, L.E.; Vallés, E.; Gómez, E.; Palomar-Pardavé, M.; Scharifker, B.R.; Mostany, J. Three-dimensional nucleation with diffusion controlled growth: A comparative study of electrochemical phase formation from aqueous and deep eutectic solvents. J. Electroanal. Chem. 2017, 793, 119-125. [CrossRef]

58. Khelladi, M.R.; Mentar, L.; Azizi, A.; Sahari, A.; Kahoul, A. Electrochemical nucleation and growth of copper deposition onto FTO and n-Si(100) electrodes. Mater. Chem. Phys. 2009, 115, 385-390. [CrossRef]

59. Méndez-Vilas, A.; González-Martín, M.L.; Labajos-Broncano, L.; Nuevo, M.J. Artifacts in AFM images revealed using friction maps. Appl. Surf. Sci. 2004, 238, 42-46. [CrossRef]

60. Aragón, A.; Figueroa, M.G.; Gana, R.E.; Zagal, J.H. Effect of a polyethoxylate surfactant on the electrodeposition of tin. J. Appl. Electrochem. 1992, 22, 558-562. [CrossRef]

61. Zhao, X.; Ando, Y.; Qin, L.C.; Kataura, H.; Maniwa, Y.; Saito, R. Radial breathing modes of multiwalled carbon nanotubes. Chem. Phys. Lett. 2002, 361, 169-174. [CrossRef] 
62. Gupta, R.; Singh, B.P.; Singh, V.N.; Gupta, T.K.; Mathur, R.B. Origin of radial breathing mode in multiwall carbon nanotubes synthesized by catalytic chemical vapor deposition. Carbon N. Y. 2014, 66, 724-726. [CrossRef]

63. Belin, T.; Epron, F. Characterization methods of carbon nanotubes: A review. Mater. Sci. Eng. B Solid-State Mater. Adv. Technol. 2005, 119, 105-118. [CrossRef]

64. Rumyantseva, M.N.; Gaskov, A.M.; Rosman, N.; Pagnier, T.; Morante, J.R. Raman surface vibration modes in nanocrystalline SnO2: Correlation with gas sensor performances. Chem. Mater. 2005, 17, 893-901. [CrossRef]

65. Singh, B.P.; Samal, S.; Nayak, S.; Majhi, S.M.; Besra, L.; Bhattacharjee, S. The production of a multi-walled carbon nanotube/hexamethylene diisocyanate nanocomposite coating on copper by electrophoretic deposition. Surf. Coat. Technol. 2011, 206, 1319-1326. [CrossRef]

66. Hu, C.; Chu, C. Electrochemical impedance characterization of polyaniline-coated graphite electrodes for electrochemical capacitors-Effects of film coverage/thickness and anions. J. Electroanal. Chem. 2001, 503, 105-116. [CrossRef]

(C) 2019 by the authors. Licensee MDPI, Basel, Switzerland. This article is an open access article distributed under the terms and conditions of the Creative Commons Attribution (CC BY) license (http://creativecommons.org/licenses/by/4.0/). 